\title{
Effective Removal of Malachite Green from Aqueous Solutions Using Magnetic Nanocomposite: Synthesis, Characterization, and Equilibrium Study
}

\author{
Ali Q. Alorabi (iD) \\ Chemistry Department, Faculty of Science, Albaha University, P.O. Box 1988, Al Baha 65779, Saudi Arabia \\ Correspondence should be addressed to Ali Q. Alorabi; aalorabi@bu.edu.sa
}

Received 30 June 2021; Revised 11 August 2021; Accepted 21 August 2021; Published 15 September 2021

Academic Editor: George Kyzas

Copyright (c) 2021 Ali Q. Alorabi. This is an open access article distributed under the Creative Commons Attribution License, which permits unrestricted use, distribution, and reproduction in any medium, provided the original work is properly cited.

\begin{abstract}
In this work, magnetized activated Juniperus procera leaves $\left(\mathrm{Fe}_{3} \mathrm{O}_{4} @ \mathrm{AJPL}\right)$ were successfully prepared via chemical activation of JPL and in situ coprecipitation with $\mathrm{Fe}_{3} \mathrm{O}_{4} \cdot \mathrm{A} \mathrm{Fe}_{3} \mathrm{O}_{4} @ \mathrm{AJPL}$ nanocomposite was successfully applied for the elimination of malachite green $(\mathrm{MG})$ dye from aqueous media. The prepared $\mathrm{Fe}_{3} \mathrm{O}_{4} @ \mathrm{AJPL}$ adsorbent was characterized by SEM, EDX, TEM, $\mathrm{XRD}$, FTIR, TGA, and BET surface area analyses. The BET surface area and pore size of the $\mathrm{Fe}_{3} \mathrm{O}_{4} @ \mathrm{AJPL}$ nanocomposite were found to be $38.44 \mathrm{~m}^{2} / \mathrm{g}$ and $10.6 \mathrm{~nm}$, respectively. The XRD and FTIR results indicated the formation of a $\mathrm{Fe}_{3} \mathrm{O}_{4} @ \mathrm{AJPL}$ nanocomposite. Different parameters, such as $\mathrm{pH}$ of the solution (3-8), adsorbent dosage (10-100 $\mathrm{mg})$, temperature (25-45 $\mathrm{C}$ ), contact time (5-240 min), and initial MG concentrations (20-350 mg/L), for the elimination of the MG dye using $\mathrm{Fe}_{3} \mathrm{O}_{4} @ \mathrm{AJPL}$ were optimized and found to be $7,50 \mathrm{mg}, 45^{\circ} \mathrm{C}, 120 \mathrm{~min}$, and $150 \mathrm{mg} / \mathrm{L}$, respectively. The nonlinear isotherm and kinetic studies exhibited a better fitting to second-order kinetic and Langmuir isotherm models, with a maximum monolayer adsorption capacity of $318.3 \mathrm{mg} / \mathrm{g}$ at $45^{\circ} \mathrm{C}$, which was highly superior to the previously reported magnetic nanocomposite adsorbents. EDX analyses confirmed the presence of nitrogen on the $\mathrm{Fe}_{3} \mathrm{O}_{4} @ \mathrm{AJPL}$ surface after MG adsorption. The calculated thermodynamic factors indicated endothermic and spontaneous processes. The desorption of MG dye from $\mathrm{Fe}_{3} \mathrm{O}_{4} @ \mathrm{AJPL}$ was performed using a solution of $90 \%$ ethanol. Finally, it could be concluded that the designed $\mathrm{Fe}_{3} \mathrm{O}_{4} @ \mathrm{AJPL}$ magnetic nanocomposite will be a cost-effective and promising adsorbent for the elimination of MG from aqueous media.
\end{abstract}

\section{Introduction}

Water pollution by organic wastes produced by human activities is considered as one of the most dangerous environmental problems which have threatened human health and other living organisms. Dyes are widely utilized in different industries such as pharmaceuticals, paper, plastics, leather, and textiles. Malachite green (MG) has been extensively used in various fields such as in food processing, textile, cosmetic, pharmaceutical, plastic, and paper industries [1]. MG is used in aquaculture industries due to its great fungicide and bactericidal efficacy. Thus, it is extremely toxic to humans, plants, and aquatic fauna [2,3], and it can cause carcinogenesis damage to the kidney and liver $[4,5]$. Due to the toxicity and carcinogenic effect of MG dye ions, their removal from the aqueous environment is highly demanded. Therefore, the removal of dyes such as MG from wastewaters or surface waters is mandatory for the protection of human health. Different techniques were developed by researchers for the dye removal from the wastewater including membrane [6], photodegradation [7, 8], oxidation [9], electrochemical [10] ion exchange [11], and adsorption methods [12-14]. Among these techniques, adsorption is a successful, effective, and economical technique that is used to eliminate dyes from the polluted water as compared to other techniques $[15,16]$.

Many adsorbent materials were obtained from natural materials such as chitosan [17] and alginate beads [18]; wastes of agricultural activities, for example, almond shell [19], garlic peel [20], coffee waste [21], sugarcane bagasse 
[22], orange peels [23], banana peels [24], and peanut hull; and industrial waste, i.e., fly ash [25] for the elimination of dyes from aqueous media. Among the tested natural materials, leaf-based materials have received great attention as they possess various characteristics such as their low cost, easy preparation, and availability in large quantities. Leaves are used as an adsorbent material for the elimination of MG dye from wastewater by reducing the amount of waste produced [26]. Gupta et al. [27] have prepared Ashoka (Saraca asoca) leaf powder and tested for the elimination of brilliant green (BG), malachite green (MG), rhodamine $\mathrm{B}(\mathrm{RB})$, and methylene blue (MB) from an aqueous solution with $125,83.3,66.6$, and $90.9 \mathrm{mg} / \mathrm{g}$, respectively, as the maximum adsorption capacity. The treatment of the raw leaf-based material with different chemical reagents such as acids and bases could improve their adsorption properties toward the removal of dyes [28, 29].

Recently, it has been reported that biosorbent treated with $\mathrm{H}_{2} \mathrm{O}_{2}$ improved the capacity of dye adsorption from the solution since the $\mathrm{H}_{2} \mathrm{O}_{2}$ could increase oxygencontaining functional groups on the surface of the adsorbent and thus augment its capability to remove dyes from aqueous media [30, 31]. As we know, nonmagnetic material adsorbents suffer from the difficulty of isolation of adsorbate-loaded absorbents from aqueous media after the adsorption process due to their small particle size. To overcome this problem, the use of magnetism has been proposed by several researchers. Magnetite nanoparticles $\left(\mathrm{Fe}_{3} \mathrm{O}_{4}\right)$ attract significant attention due to their unique large surface area, and these possess high saturation magnetization and can easily isolate toxic pollutants from aqueous solutions by using a magnet without using centrifugation and filtration compared to conventional adsorbents [32]. New economical, highly effective, and locally available biosorbents are still under development. Juniperus procera leaves are the most abundant plant in Saudi Arabia and many countries such as Lebanon, Bosnia, and Turkey [33-36]. Magnetic modification of low-cost adsorbents such as Juniperus procera leaves (JPL) could lead to materials appropriate for environmental applications. After a thorough literature survey, we have concluded that there are no previous studies reporting the activation of Juniperus procera leaves with $\mathrm{H}_{2} \mathrm{O}_{2}$ to increase the oxygen-containing functional groups on its surface. To our best knowledge, this is the first work to report the synthesis of a $\mathrm{Fe}_{3} \mathrm{O}_{4} @$ activated Juniperus procera leaf nanocomposite.

This study was aimed at synthesizing a new $\mathrm{Fe}_{3} \mathrm{O}_{4} @$ activated Juniperus procera leaf nanocomposite $\left(\mathrm{Fe}_{3} \mathrm{O}_{4} @ \mathrm{AJPL}\right)$ via chemical activation and in situ coprecipitation methods. The prepared adsorbent was applied for removal of dyes from aqueous media. The $\mathrm{Fe}_{3} \mathrm{O}_{4} @ \mathrm{AJPL}$ adsorbent was characterized by SEM, EDX, TEM, XRD, TGA, FTIR, and BET surface area analysis. The impact of various parameters on the MG dye adsorption onto $\mathrm{Fe}_{3} \mathrm{O}_{4} @ \mathrm{AJPL}$ adsorbent such as solution $\mathrm{pH}$, adsorbent dosage, contact time, initial MG concentrations, and temperature was achieved. The isotherm and kinetic data were analyzed by applying nonlinear equation models. Thermodynamic factors were also calculated.

\section{Experiments}

2.1. Chemicals and Instrumentation. Malachite green (MG), hydrogen peroxide $\left(\mathrm{H}_{2} \mathrm{O}_{2}, 30 \%\right)$, ferric chloride $\left(\mathrm{FeCl}_{3} \cdot 6 \mathrm{H}_{2} \mathrm{O}, 97 \%\right)$, ethanol $\left(\mathrm{C}_{2} \mathrm{H}_{5} \mathrm{OH}, 99.8 \%\right)$, and ferrous chloride $\left(\mathrm{FeCl}_{2} \cdot 4 \mathrm{H}_{2} \mathrm{O}, 98 \%\right)$ were procured from Sigma Aldrich. Nitric acid $\left(\mathrm{HNO}_{3}, 68.0-70.0 \%\right)$ sodium hydroxide $(\mathrm{NaOH}, \geq 97 \%)$, and hydrochloric acid $(\mathrm{HCl}, 36 \%)$ were procured from BDH, England. Solutions were prepared using deionized water. The crystalline structures of $A J P L, \mathrm{Fe}_{3} \mathrm{O}_{4}$, and $\mathrm{Fe}_{3} \mathrm{O}_{4} @ \mathrm{AJPL}$ were determined using an XRD-6000 (Shimadzu, Kyoto, Japan). The morphological properties of AJPL, $\mathrm{Fe}_{3} \mathrm{O}_{4}, \mathrm{Fe}_{3} \mathrm{O}_{4} @ \mathrm{AJPL}$, and $\mathrm{Fe}_{3} \mathrm{O}_{4} @ \mathrm{AJPL}-\mathrm{MG}$ were evaluated using a transmission electron microscope (TEM) and scanning electron microscope (SEM) (JEOL $200 \mathrm{kV}$, Tokyo, Japan). Fourier transform infrared spectra of activated Juniperus procera leaves (AJPL), $\mathrm{Fe}_{3} \mathrm{O}_{4} @ \mathrm{AJPL}$, and MG-saturated $\mathrm{Fe}_{3} \mathrm{O}_{4} @ \mathrm{AJPL}\left(\mathrm{Fe}_{3} \mathrm{O}_{4} @ \mathrm{AJPL}-\mathrm{MG}\right)$ were recorded using a Nicolet iS50, Thermo Scientific (Madison, WI, USA). The elemental composition of adsorbents was detected by energy-dispersive X-ray (EDX) (JEOL 7600F, Tokyo, Japan). The surface area of $\mathrm{Fe}_{3} \mathrm{O}_{4} @ \mathrm{AJPL}$ was evaluated through the determination of $\mathrm{N}_{2}$ adsorptiondesorption isotherms at $-196^{\circ} \mathrm{C}$ by Micromeritics (USA). The concentration of MG was determined using a UVvisible spectrophotometer (Shimadzu 2450) at $616 \mathrm{~nm}$.

2.2. Chemical Treatment of Juniperus procera Leaves. Juniperus procera leaves (JPL) were collected from Al Baha Province, Saudi Arabia. The leaves were washed with distilled water and dried for 7 days at room temperature $\left(22-27^{\circ} \mathrm{C}\right)$ and ground using an electrical grinder. To increase oxygen-containing functional groups on the JPL surface, the JPL was treated with $\mathrm{H}_{2} \mathrm{O}_{2}$ by using the reported methods [30, 31]. Briefly, $20 \mathrm{~g}$ of the obtained JPL powder was immersed in $200 \mathrm{~mL}$ of $10 \% \mathrm{H}_{2} \mathrm{O}_{2}$ and stirred for $24 \mathrm{~h}$. Then, the sample was filtered off and was washed several times with deionized water. Following, $20 \mathrm{~g}$ of the AJPL powder was added into $200 \mathrm{~mL}$ of $1 \mathrm{M} \mathrm{NaOH}$ for removal of the impurities from the surface of JPL powder, resulting in improvement of the surface roughness of particles, formation of a pore structure, and opening of more hydroxyl groups and other reactive functional groups on its surface. Therefore, the removal of surface impurities can improve the adsorption properties of the JPL powder $[37,38]$. The $J P L$ powder was stirred for $24 \mathrm{~h}$ at $25^{\circ} \mathrm{C}$. The resulting $A J P L$ powder was washed with D.I. water and dried at $25^{\circ} \mathrm{C}$ for 3 days. Finally, the $A J P L$-obtained material was ground again to obtain a uniform particle size (Figure 1).

\subsection{Magnetization of Juniperus procera Leaves} $\left(\mathrm{Fe}_{3} \mathrm{O}_{4} @ A J P L\right)$. The magnetization of AJPL powder was performed using the in situ coprecipitation method. Briefly, in a three-necked round bottom flask containing $90 \mathrm{~mL}$ D.I. water, $1.5 \mathrm{~g}$ of AJPL powder was suspended. To this mixture, $0.715 \mathrm{~g}$ of $\mathrm{FeCl}_{2} \cdot 4 \mathrm{H}_{2} \mathrm{O}$, and $2.15 \mathrm{~g}$ of $\mathrm{FeCl}_{3} \cdot 6 \mathrm{H}_{2} \mathrm{O}\left(\mathrm{Fe}^{2+}\right.$ :$\mathrm{Fe}^{3+}=1: 2$ molar ratio) were added and mechanically stirred for $20 \mathrm{~min}$ and heated to $80^{\circ} \mathrm{C}$, and then, $10 \mathrm{~mL}^{\circ} \mathrm{NH}_{4} \mathrm{OH}$ was added dropwise over a period of $2 \mathrm{hrs}$. The obtained 


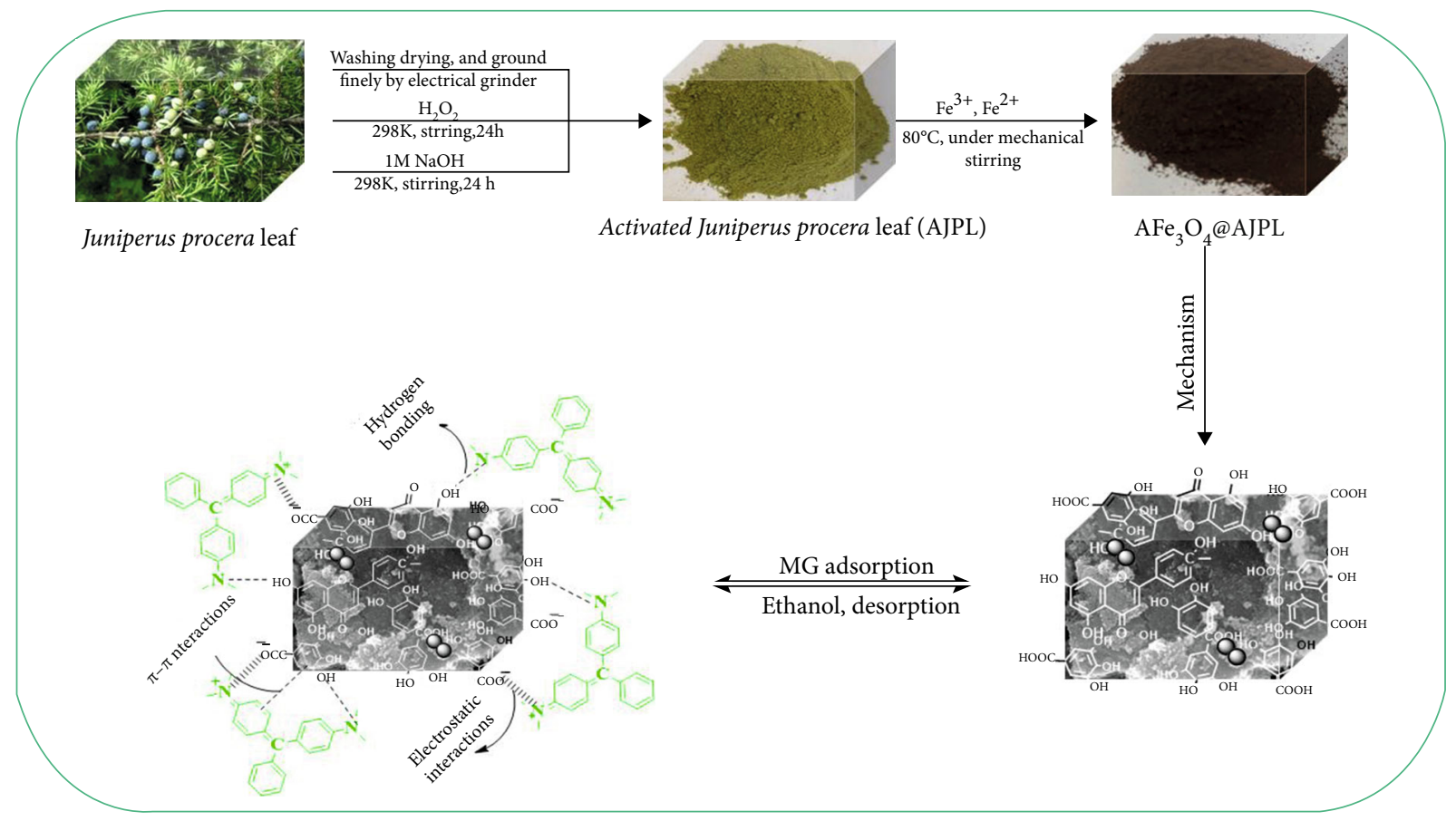

Figure 1: Synthesis of $\mathrm{Fe}_{3} \mathrm{O}_{4} @ \mathrm{AJPL}$ nanocomposite and its mechanism of adsorption-desorption behavior for MG dye ions.

black precipitate (termed $\mathrm{Fe}_{3} \mathrm{O}_{4} @ \mathrm{AJPL}$ ) was collected by external magnetic field and washed with ethanol and D.I. water. Finally, the $\mathrm{Fe}_{3} \mathrm{O}_{4} @ \mathrm{AJPL}$ was dried at $60^{\circ} \mathrm{C}$ for $24 \mathrm{~h}$. Figure 1 demonstrates the preparation scheme of the $\mathrm{Fe}_{3} \mathrm{O}_{4} @ \mathrm{AJPL}$ nanocomposite.

2.4. Adsorption Studies. The batch experiment method was conducted to select the best parameters for the adsorption process. The impact of adsorption parameters on MG dye adsorption by $\mathrm{Fe}_{3} \mathrm{O}_{4} @ \mathrm{AJPL}$ adsorbents including adsorbent dosage (10-100 $\mathrm{mg}), \mathrm{pH}(3-8)$, temperature $\left(25-45^{\circ} \mathrm{C}\right)$, contact time (5-240 min), and initial MG dye concentration $(20-350 \mathrm{mg} / \mathrm{L})$ was achieved. The general procedure was as follows: the desired quantity of $\mathrm{Fe}_{3} \mathrm{O}_{4} @ \mathrm{AJPL}$ adsorbents was taken in a $250 \mathrm{~mL}$ Erlenmeyer flask containing a $50 \mathrm{~mL}$ solution of MG with a given concentration, and then, the sample solution $\mathrm{pH}$ was adjusted using a $0.1 \mathrm{M} \mathrm{HCl}$ or $0.1 \mathrm{M} \mathrm{NaOH}$ to the desired $\mathrm{pH}$. Then, the sample solution was shaken at $100 \mathrm{rpm}$ for a specific time. After that, the sample was separated using a magnet, and the residual MG concentration was measured using a UV/Vis spectrophotometer at $616 \mathrm{~nm}$. The adsorption efficiency $\left(R_{\mathrm{e}}, \%\right)$ and adsorbent capacity $\left(q_{\mathrm{e}}, \mathrm{mg} / \mathrm{g}\right)$ were determined according to the following equations, respectively:

$$
\begin{gathered}
R_{\mathrm{e}}(\%)=\frac{C_{\mathrm{o}}-C_{\mathrm{e}}}{C_{\mathrm{o}}} \times 100, \\
q_{\mathrm{e}}=\left(C_{\mathrm{o}}-C_{\mathrm{e}}\right) \frac{V}{m},
\end{gathered}
$$

where $C_{\mathrm{o}}(\mathrm{mg} / \mathrm{L})$ and $C_{\mathrm{e}}(\mathrm{mg} / \mathrm{L})$ represent the initial and equilibrium concentrations of MG, respectively; $m$ is the amount of $\mathrm{Fe}_{3} \mathrm{O}_{4} @ \mathrm{AJPL}$ adsorbents $(\mathrm{g})$; and $V(\mathrm{~L})$ is the solution volume. For the desorption study, the separated adsorbent was placed into $50 \mathrm{~mL}$ of $90 \%$ ethanol or $\mathrm{HCl}$ $(0.1 \mathrm{M})$ and $\mathrm{HNO}_{3}(0.1 \mathrm{M})$ solution. Then, the sample solution was shaken at $100 \mathrm{rpm}$ for $120 \mathrm{~min}$. After that, the MG dye concentrations of the sample isolated with a magnet were determined using a UV/Vis spectrophotometer at $616 \mathrm{~nm}$. The $\%$ desorption was calculated by using the following equation:

$$
\begin{aligned}
\% \text { desorption }= & \frac{\text { Concentration of } M G \text { desorbed by the ethanol }}{\text { Initial concentration of } \mathrm{MG} \text { adsorbed on } \mathrm{Fe}_{3} \mathrm{O}_{4} @ \mathrm{AJPL}} \\
& \times 100 .
\end{aligned}
$$

\section{Results and Discussion}

3.1. Synthesis and Characterization of $\mathrm{Fe}_{3} \mathrm{O}_{4} @ A J P L$. Juniperus procera leaves (JPL) were activated by using $\mathrm{H}_{2} \mathrm{O}_{2}$ and $\mathrm{NaOH}$ reagent. $\mathrm{H}_{2} \mathrm{O}_{2}$ is a strong oxidant, inexpensive, and clean. The use of $\mathrm{H}_{2} \mathrm{O}_{2}$ and $\mathrm{NaOH}$ is important to increase oxygen-containing functional groups on the JPL surface and improve the adsorption properties of JPL powder by removing the impurities from the surface of the JPL powder. AJPL carries hydroxyl, carboxyl, and carbonyl groups. Activated Juniperus procera leaves were successfully converted to the magnetized activated Juniperus procera leaves $\left(\mathrm{Fe}_{3} \mathrm{O}_{4} @ \mathrm{AJPL}\right)$ via in situ coprecipitation. $\mathrm{Fe}_{3} \mathrm{O}_{4} @ \mathrm{AJPL}$ has the ability to separate MG dye from aqueous solutions by using an external magnetic field, and it has a large surface area $\left(116.9517 \mathrm{~m}^{2} / \mathrm{g}\right)$ and pore size $(9.48 \mathrm{~nm})$. It can easily separate the MG dye from aqueous solutions by using an external magnetic field. The $\mathrm{Fe}_{3} \mathrm{O}_{4} @ \mathrm{AJPL}$ nanocomposite contains different functional groups $(\mathrm{COOH}$, 


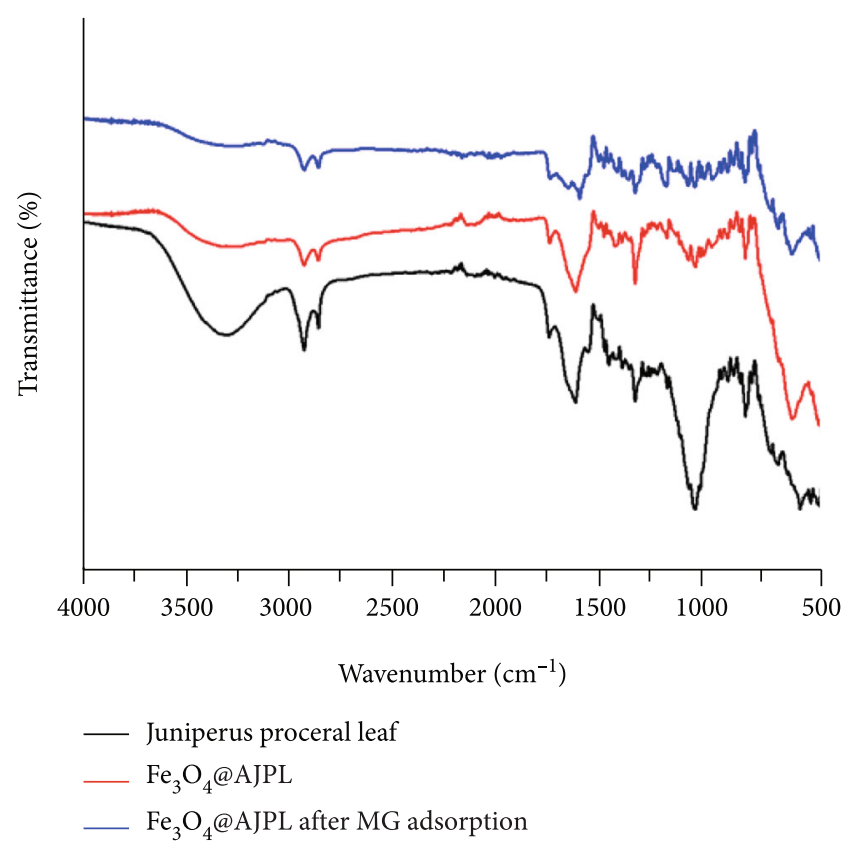

(a)

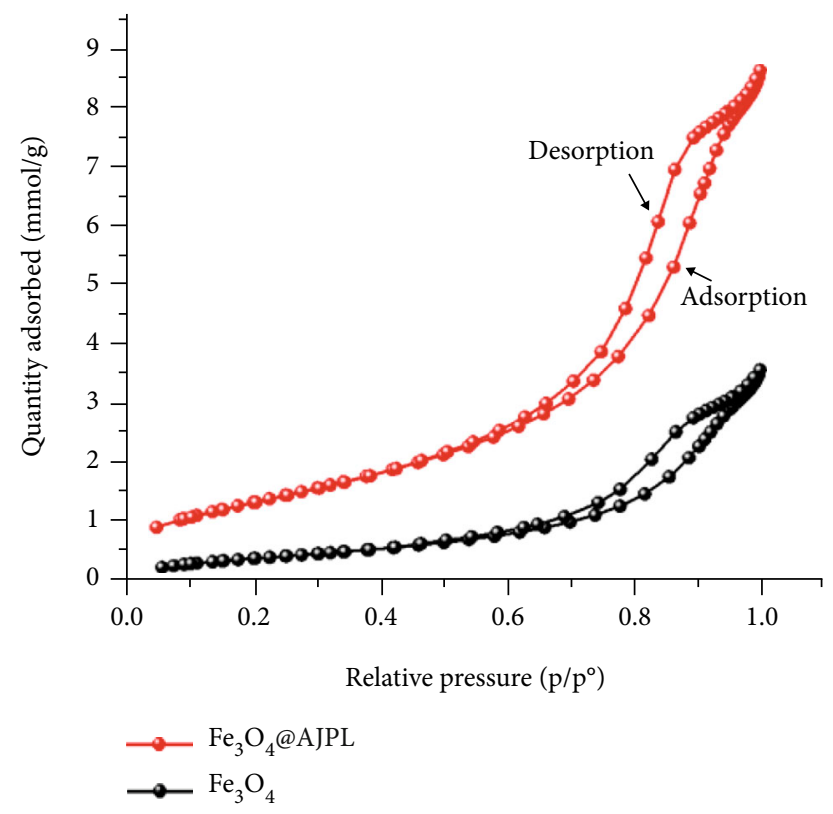

(c)

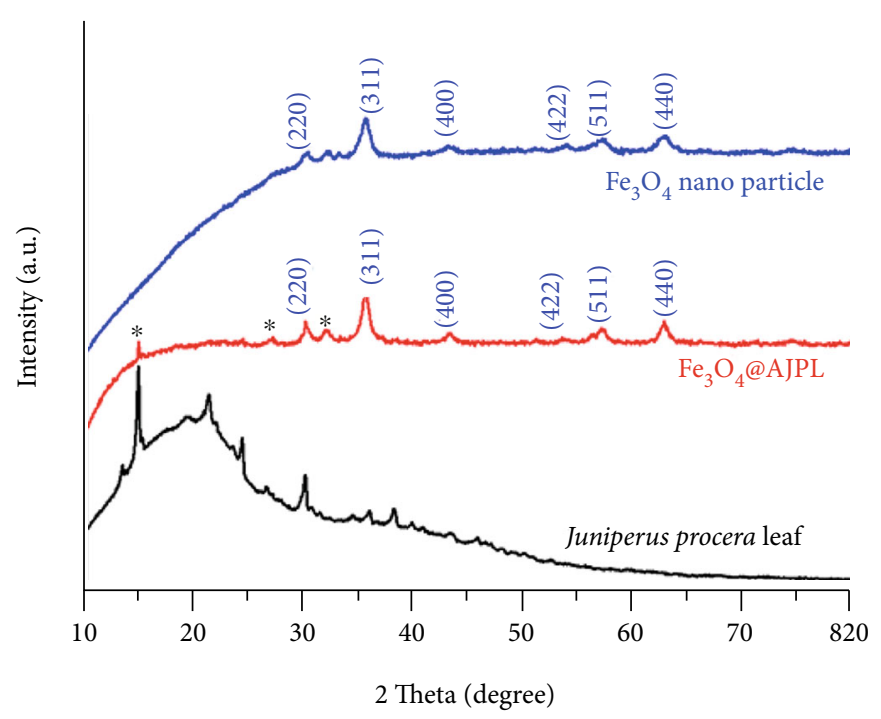

(b)

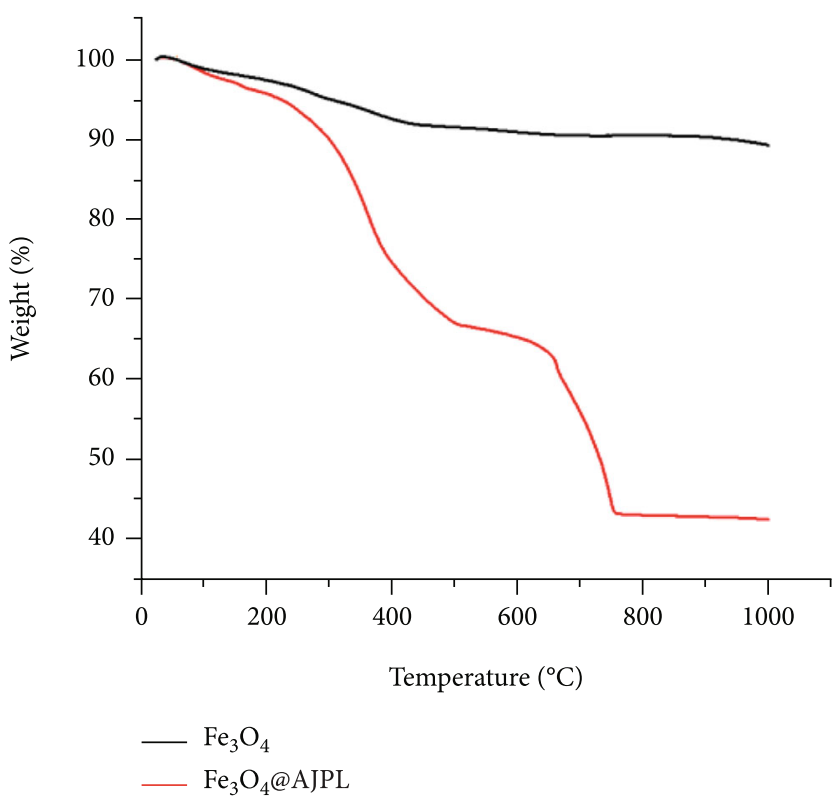

(d)

FIGURE 2: (a) FT-IR spectra, (b) XRD plot, (c) BET adsorption-desorption analysis, and (d) TGA analysis of adsorbents.

$\mathrm{OH}, \mathrm{C}=\mathrm{O}$ ) which can adsorb MG ions by for $\pi-\pi$ stacking, $\mathrm{H}$-bonding, and electrostatic attraction (Figure 1).

Figure 2(a) displays the FTIR of $A J P L, \mathrm{Fe}_{3} \mathrm{O}_{4} @ \mathrm{AJPL}$ before adsorption, and MG-saturated $\mathrm{Fe}_{3} \mathrm{O}_{4} @ \mathrm{AJPL}$ $\left(\mathrm{Fe}_{3} \mathrm{O}_{4} @ \mathrm{AJPL}-\mathrm{MG}\right)$ adsorbent. In the spectrum of $A J P L$, the broad band centered at $3320 \mathrm{~cm}^{-1}$ is attributed to the $\mathrm{OH}$ group, suggesting the presence of a phenolic group [39]. The bands at 1731 and $1606 \mathrm{~cm}^{-1}$ ascribed to $\mathrm{C}=\mathrm{O}$ and the one at $1026 \mathrm{~cm}^{-1}$ corresponding to $\mathrm{C}-\mathrm{O}-\mathrm{C}$ groups indicate the existence of carboxylic acid derivatives. Furthermore, the observed band of $\mathrm{C}=\mathrm{C}$ stretching vibration at
$1549 \mathrm{~cm}^{-1}$ as well as the C-H out-of-plane bending vibrations at $776 \mathrm{~cm}^{-1}$ is possibly characterizing the aromatic rings. Additional peaks of $\mathrm{CH}$ modes were also identified, e.g., at about $2943 \mathrm{~cm}^{-1}$. In the spectrum of $\mathrm{Fe}_{3} \mathrm{O}_{4} @ \mathrm{AJPL}$, a new band at $560 \mathrm{~cm}^{-1}$ assigned to the distinctive band of $\mathrm{Fe}-\mathrm{O}$ stretching vibration was observed, confirming the presence of $\mathrm{Fe}_{3} \mathrm{O}_{4}$ nanoparticles [40, 41]. Moreover, it is observed that the modification of $A J P L$ with $\mathrm{Fe}_{3} \mathrm{O}_{4}$ nanoparticles has resulted in intensity reduction of some characteristic peaks including the $\mathrm{OH}$ and $\mathrm{C}-\mathrm{O}-\mathrm{C}$ peaks. The spectra of the MG-loaded $\mathrm{Fe}_{3} \mathrm{O}_{4} @ \mathrm{AJPL}$ showed shifts in the bands of 
some functional groups such as $\mathrm{C}=\mathrm{O}, \mathrm{OH}$, and $\mathrm{C}-\mathrm{O}-\mathrm{C}$ from 1731,3320 , and $1026 \mathrm{~cm}^{-1}$ to 1721,3329 , and $1023 \mathrm{~cm}^{-1}$, respectively, due to adsorptive interaction.

Figure 2(b) shows the XRD pattern of AJPL, $\mathrm{Fe}_{3} \mathrm{O}_{4}$ nanoparticles, and $\mathrm{Fe}_{3} \mathrm{O}_{4} @ \mathrm{AJPL}$ nanocomposite. As implied in Figure 2(b), the characteristic peaks of $\mathrm{Fe}_{3} \mathrm{O}_{4}$ nanoparticles and the $\mathrm{Fe}_{3} \mathrm{O}_{4} @ \mathrm{AJPL}$ nanocomposite perfectly matched the face-centered cubic crystalline which was confirmed by $2 \theta$ values of $30.24^{\circ}, 35.56^{\circ}, 43.22^{\circ}, 57.11^{\circ}$, and $62.76^{\circ}$ to (220), (311), (400), (511), and (440) planes, respectively [42]. The diffraction peaks for AJPL are $13.45^{\circ}, 14.83^{\circ}$, $21.2^{\circ}, 24.29^{\circ}, 30.02^{\circ}, 35.8^{\circ}$, and $38.15^{\circ}$. After modification of magnetite nanoparticles with AJPL, new peaks appeared at $2 \theta=14.9^{\circ}$ and $27.02^{\circ}$ which matched to the strong peaks in the XRD pattern of leaves [43]. Therefore, these results indicated that the $\mathrm{Fe}_{3} \mathrm{O}_{4} @ \mathrm{AJPL}$ nanocomposite was successfully synthesized.

Figure 2(c) displays the $\mathrm{N}_{2}$ adsorption/desorption isotherms of $\mathrm{Fe}_{3} \mathrm{O}_{4}$ nanoparticles and the $\mathrm{Fe}_{3} \mathrm{O}_{4} @ \mathrm{AJPL}$ nanocomposite. The surface area, pore volume, and pore size were found to be $116.9517 \mathrm{~m}^{2} / \mathrm{g}, 0.322 \mathrm{~cm}^{3} / \mathrm{g}$, and $9.48 \mathrm{~nm}$ for $\mathrm{Fe}_{3} \mathrm{O}_{4}$ nanoparticles and $38.44 \mathrm{~m}^{2} / \mathrm{g}, 0.136 \mathrm{~cm}^{3} / \mathrm{g}$, and $10.6 \mathrm{~nm}$ for the $\mathrm{Fe}_{3} \mathrm{O}_{4} @ \mathrm{AJPL}$ nanocomposite. The $\mathrm{N}_{2}$ adsorption-desorption curve of both adsorbents exhibited a type IV isotherm, suggesting the presence of mesopores in both adsorbents.

Figure 2(d) shows thermogravimetric analysis (TGA) of $\mathrm{Fe}_{3} \mathrm{O}_{4}$ and $\mathrm{Fe}_{3} \mathrm{O}_{4} @ \mathrm{AJPL}$. In the case of $\mathrm{Fe}_{3} \mathrm{O}_{4}$, about 10\% is the total weight loss in the temperature range from $25^{\circ} \mathrm{C}$ to $1000^{\circ} \mathrm{C}$ due to the removal of the adsorbed water and conversion of hydroxide to oxide [44]. In the case of the $\mathrm{Fe}_{3} \mathrm{O}_{4} @ \mathrm{AJPL}$ nanocomposite, it is a three-stage thermal degradation. The first stage from $25-180^{\circ} \mathrm{C}(3 \%)$ is related to the loss of moisture and adsorbed water. $7 \%$ and $50 \%$ weight loss were observed between the temperature ranges 180 $320^{\circ} \mathrm{C}$ and $320-800^{\circ} \mathrm{C}$ in the second and third stages, respectively, due to decomposition of molecular organic compounds such as flavonoids of JPL in $\mathrm{Fe}_{3} \mathrm{O}_{4} @ \mathrm{AJPL}$ [45]. The total weight losses of $\mathrm{Fe}_{3} \mathrm{O}_{4} @ \mathrm{AJPL}$ and pure magnetite nanoparticles were $60 \%$ and $10 \%$, respectively, which confirmed the formation of the $\mathrm{Fe}_{3} \mathrm{O}_{4} @ \mathrm{AJPL}$ nanocomposite.

Figure 3 shows the SEM-EDX image results of the AJPL powder, $\mathrm{Fe}_{3} \mathrm{O}_{4}, \mathrm{Fe}_{3} \mathrm{O}_{4} @ \mathrm{AJPL}$, and $\mathrm{MG}$ dye-saturated $\mathrm{Fe}_{3} \mathrm{O}_{4} @ \mathrm{AJPL}$ adsorbents. The surface structure of the AJPL powder is rough with the existence of some pore and crack sites (Figure 3(a)). After modifying the AJPL powder with magnetite nanoparticles, the magnetite nanoparticles are dispersed in the surface of AJPL (Figure 3(c)). The surface of $\mathrm{Fe}_{3} \mathrm{O}_{4}$ nanoparticles shows a spherical shape with diameters in the range of $12-25 \mathrm{~nm}$ (Figure 3(e)). The SEM image of the $\mathrm{Fe}_{3} \mathrm{O}_{4} @ \mathrm{AJPL}$ loading MG showed a different morphology than before adsorption, which was well occupied with the MG dye as implied in Figure 3(g), indicating that the MG dye was successfully adsorbed on the $\mathrm{Fe}_{3} \mathrm{O}_{4} @ \mathrm{AJPL}$ adsorbent. The EDX of the AJPL powder (Figure 3(b)) revealed the presence of mainly C (30.68\%) and O (30.50\%) and small amounts of $\mathrm{Ca}, \mathrm{Al}, \mathrm{K}$, and $\mathrm{Si}$. After modifying $A J P L$ with magnetite nanoparticles, it was clearly observed that a new peak from iron (45.33\%) appeared and increased in the intensity of oxygen (38.27\%), confirming the synthesis of $\mathrm{Fe}_{3} \mathrm{O}_{4} @ \mathrm{AJPL}$ successfully (Figure 3(d)).65.32\% of iron and $34.68 \%$ of oxygen were observed in the EDX spectrum of pure magnetite nanoparticles (Figure 3(e)). After MG dye was saturated on the $\mathrm{Fe}_{3} \mathrm{O}_{4} @ \mathrm{AJPL}$ nanocomposite, a new peak of nitrogen was observed, indicating the successful adsorption of MG dye on the $\mathrm{Fe}_{3} \mathrm{O}_{4} @ \mathrm{AJPL}$ adsorbent Figure 3(h). Figure 4(a) displays the TEM images of $\mathrm{Fe}_{3} \mathrm{O}_{4} @ \mathrm{AJPL}$ nanocomposite. A small degree of agglomeration with a spherical shape was observed. The particle size was found to be $9 \mathrm{~nm}$ Figure 4(b). Figure 4(c) displays the lattice fringe spacing of the crystalline part $\left(\mathrm{Fe}_{3} \mathrm{O}_{4}\right)$ of the $\mathrm{Fe}_{3} \mathrm{O}_{4} @ \mathrm{AJPL}$ nanocomposite. The $\mathrm{d}$ spacing values were $0.291 \mathrm{~nm}$ and $0.252 \mathrm{~nm}$, which are attributed to the (311) and (220) planes of $\mathrm{Fe}_{3} \mathrm{O}_{4}$ nanoparticles which were confirmed by the XRD results for the cubic structure of $\mathrm{Fe}_{3} \mathrm{O}_{4}$ nanoparticles. The selected area electron diffraction (SAED) analysis shows a ring pattern which confirms the presence of crystalline $\mathrm{Fe}_{3} \mathrm{O}_{4}$ nanoparticles in the nanocomposites $\left(\mathrm{Fe}_{3} \mathrm{O}_{4} @ \mathrm{AJPL}\right)$ (Figure 4(c)).

\subsection{Adsorption Studies}

3.2.1. Adsorbate Selectivity. The prepared adsorbents AJPL and $\mathrm{Fe}_{3} \mathrm{O}_{4} @ \mathrm{AJPL}$ nanocomposite were examined for elimination of different cationic dyes such as $\mathrm{MG}, \mathrm{CV}$, and $\mathrm{MB}$ from aqueous solutions as implied in Table 1. It was noticed that, at the adsorption conditions of adsorbent dose $50 \mathrm{mg}$, initial adsorbate concentration $\left(C_{\mathrm{o}}\right)$ of $50 \mathrm{mg} / \mathrm{L}$, and temperature of $25 \mathrm{C}$, the maximum removal efficiency of $\mathrm{MG}, \mathrm{CV}$, and $\mathrm{MB}$ dyes on both AJPL and $\mathrm{Fe}_{3} \mathrm{O}_{4} @ \mathrm{AJPL}$ nanocomposite adsorbent were $98.76 \%, 94.81 \%$, and $93.20 \%$ and $99.15 \%$, $95.61 \%$, and $73.11 \%$, respectively. Accordingly, the removal of $\mathrm{MG}$ by the $\mathrm{Fe}_{3} \mathrm{O}_{4} @ \mathrm{AJPL}$ adsorbent is considerably favored due to the high performance, easy separation, and recovery of the adsorbent using external magnetism. Thus, the adsorption parameters were further studied.

3.2.2. Effect of $p H$. The impact of the solution $\mathrm{pH}$ on $\mathrm{MG}$ adsorption onto $\mathrm{Fe}_{3} \mathrm{O}_{4} @ \mathrm{AJPL}$ was tested over a range of $\mathrm{pH}$ values from 3 to 8 (MG: $20 \mathrm{mg} / \mathrm{L}$, contact time: $24 \mathrm{~h}$, adsorbent dose: $50 \mathrm{mg}$, temperature: $25^{\circ} \mathrm{C}$, and agitation: $100 \mathrm{rpm}$ ) as shown in Figure 5(a). The results indicate an increase in the adsorption capacity and removal percentage with increase in $\mathrm{pH}$ up to $\mathrm{pH}$. This increase in adsorption capacity was due to the surface charge of $\mathrm{Fe}_{3} \mathrm{O}_{4} @ \mathrm{AJPL}$ nanocomposites becoming more negative and having strong electrostatic attraction with the cationic MG dye, resulting in higher adsorption efficiency. On the contrary, under an acidic medium, the excessive protonation of the $\mathrm{Fe}_{3} \mathrm{O}_{4} @ \mathrm{AJPL}$ nanocomposite surface hindered the binding of cationic MG ions on the $\mathrm{Fe}_{3} \mathrm{O}_{4} @ \mathrm{AJPL}$ nanocomposite surface, resulting in a lower adsorption efficiency [46]. Similar trends have been reported by Asfaram et al. for the removal of MG using biosorbent Yarrowia lipolytica ISF7 [47]. Compared with $\mathrm{pH} 7$, an almost similar performance was observed at $\mathrm{pH} 8$ above which the solution becomes colorless due to the reaction occurrence between the MG and 


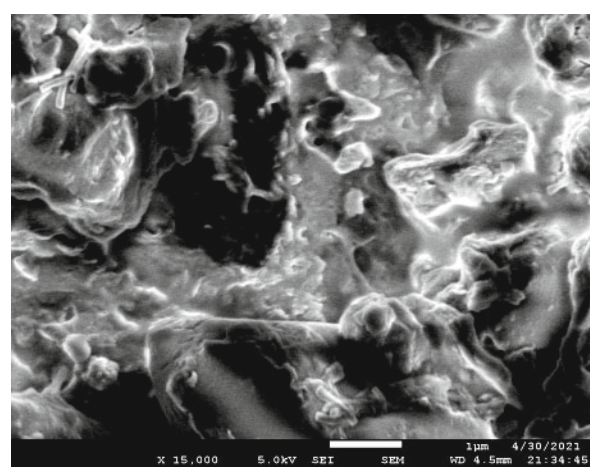

(a)

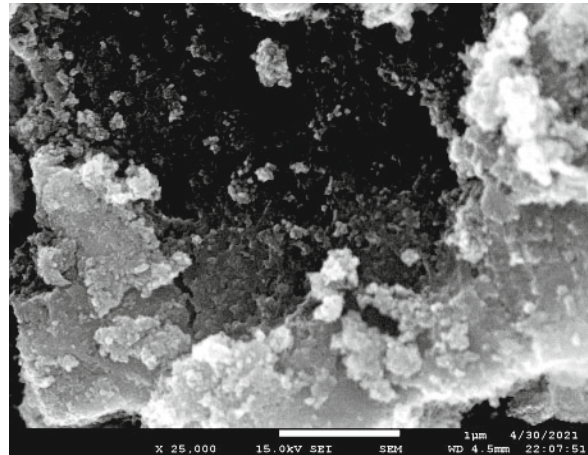

(c)

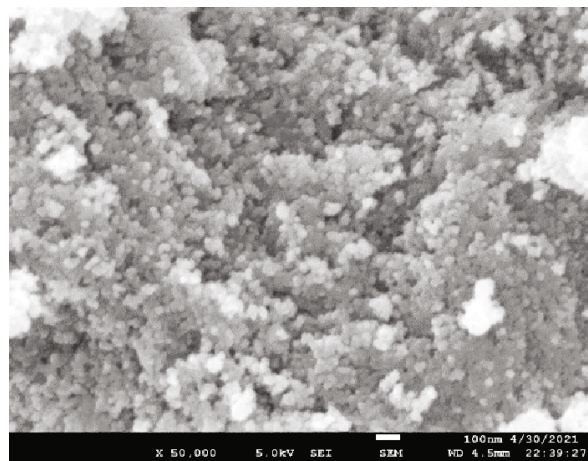

(e)

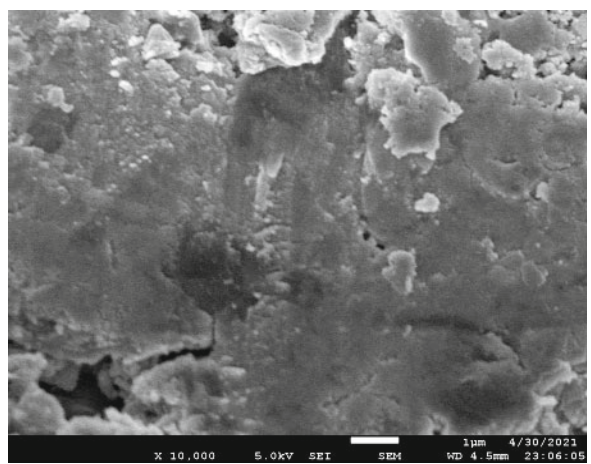

(g)

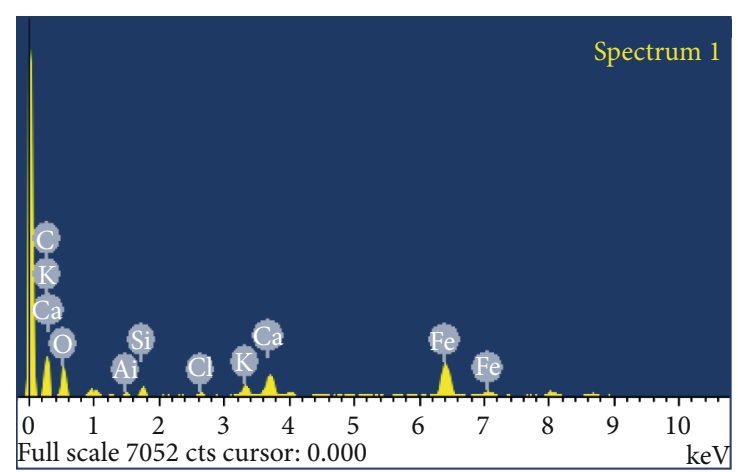

(b)

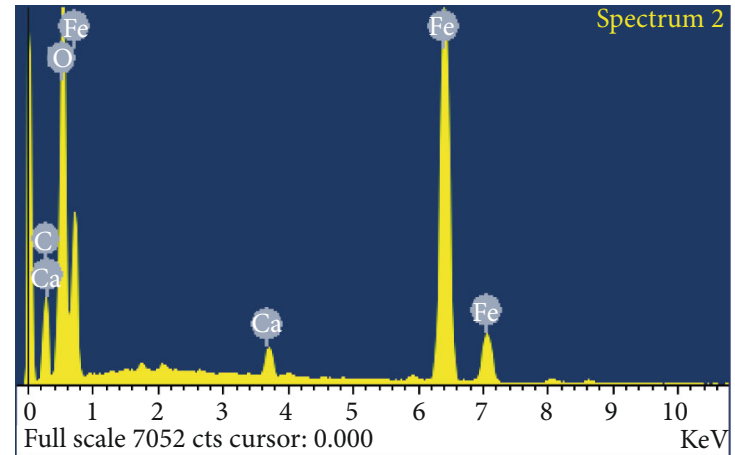

(d)

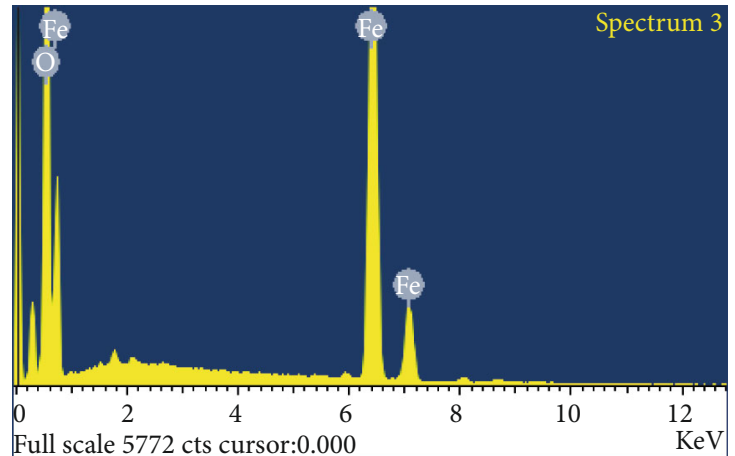

(f)

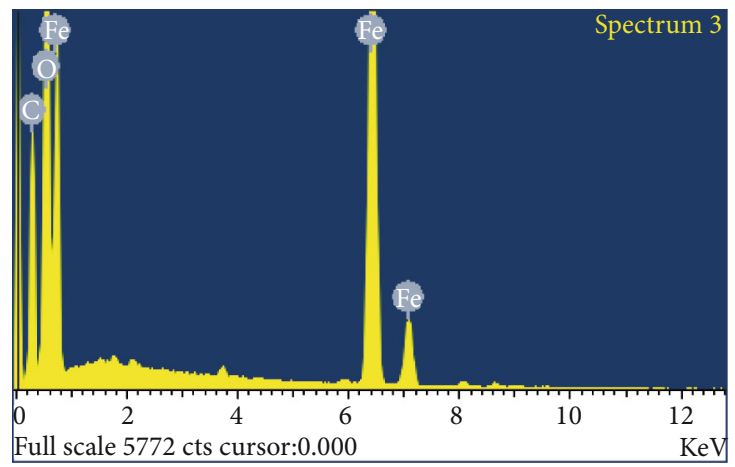

(h)

FIgURE 3: (a) SEM image, (b) EDX analysis of activated Juniperus procera leaves (AJPL), (c) SEM image, (d) EDX analysis of Fe $\mathrm{O}_{4} @ \mathrm{AJPL}$, (e) SEM images, (f) EDX analysis of magnetite nanoparticles, (g) SEM image, and (h) EDX analysis of MG adsorption onto Fe $\mathrm{O}_{4} @ \mathrm{AJPL}$. 

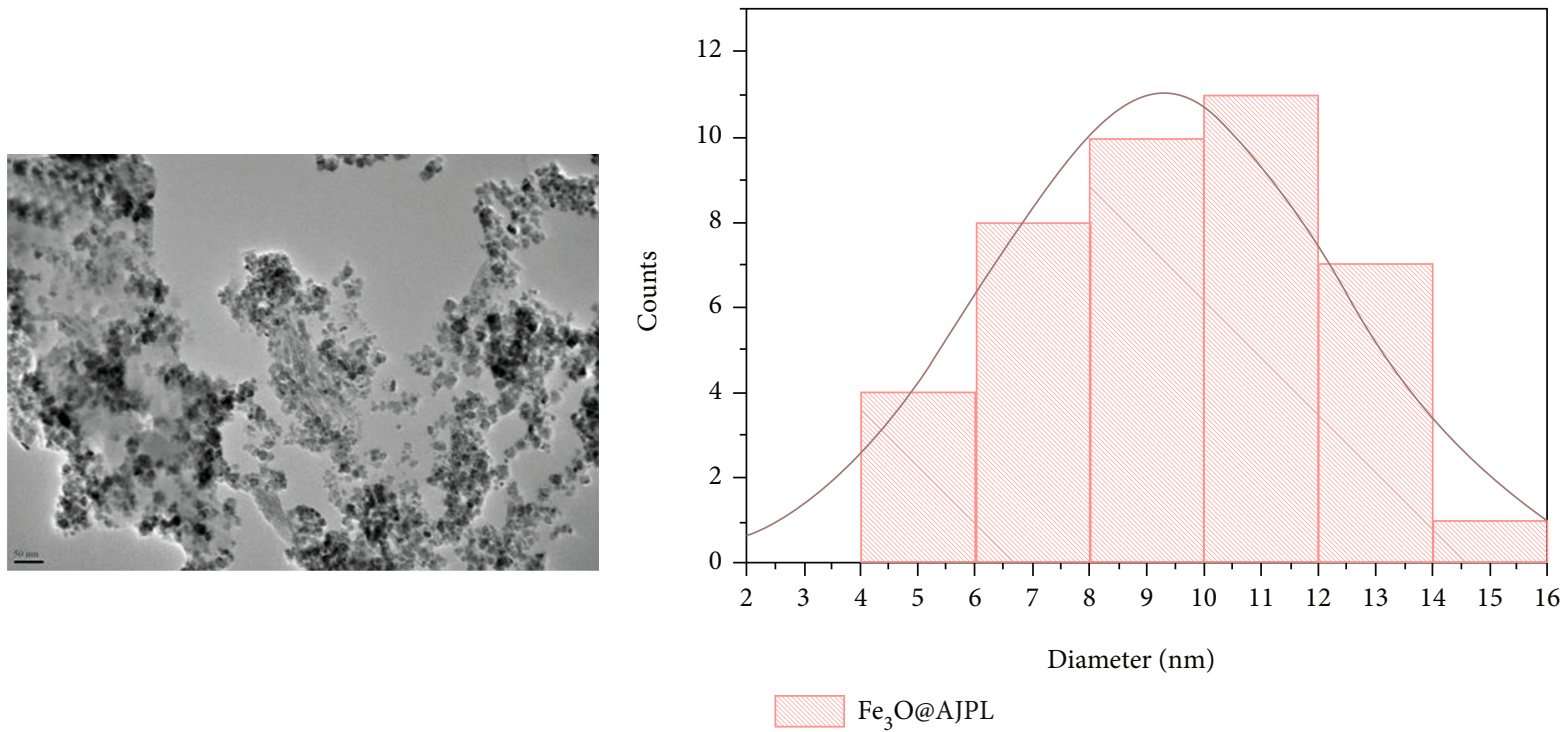

(b)

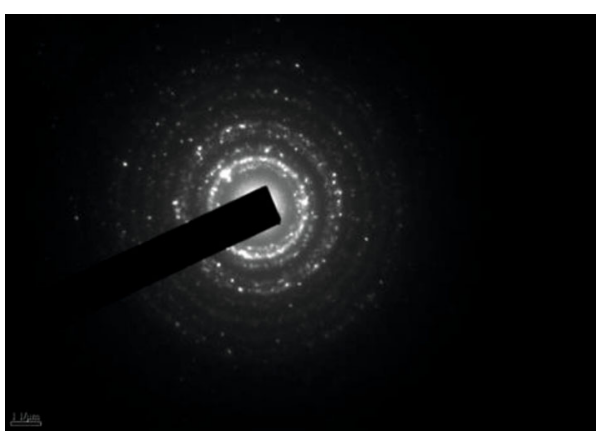

(c)

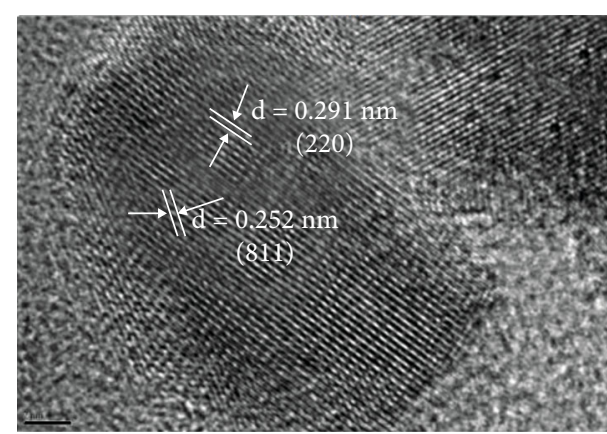

(d)

FIgUre 4: (a) TEM image, (b) size particles distribution, (c) SAED pattern, and (d) HRTEM image of Fe $\mathrm{O}_{4} @ \mathrm{AJPAL}$ adsorbent.

TABle 1: Adsorption selectivity experiments with dye solutions (conditions: dye-20 mg/L, time-24h, Fe $3 \mathrm{O}_{4} @ \mathrm{AJPAL}-50 \mathrm{mg}$, volume $-0.05 \mathrm{~L}$, temperature $-25^{\circ} \mathrm{C}$, and agitation $-100 \mathrm{rpm}$ ).

\begin{tabular}{|c|c|c|c|c|c|c|}
\hline \multirow[b]{2}{*}{ Adsorbents } & \multicolumn{2}{|c|}{ MG } & \multicolumn{2}{|c|}{$\mathrm{CV}$} & \multicolumn{2}{|c|}{$\mathrm{MB}$} \\
\hline & $\begin{array}{c}\text { Adsorption } \\
\text { capacity }(\mathrm{mg} / \mathrm{g})\end{array}$ & $\begin{array}{c}\text { Removal } \\
\text { efficiency (\%) }\end{array}$ & $\begin{array}{c}\text { Adsorption } \\
\text { capacity (mg/g) }\end{array}$ & $\begin{array}{c}\text { Removal } \\
\text { efficiency (\%) }\end{array}$ & $\begin{array}{c}\text { Adsorption } \\
\text { capacity (mg/g) }\end{array}$ & $\begin{array}{c}\text { Removal } \\
\text { efficiency (\%) }\end{array}$ \\
\hline $\begin{array}{l}\text { Activated Juniperus procera } \\
\text { leaves (AJPL) }\end{array}$ & 19.75 & 98.76 & 18.96 & 94.81 & 18.64 & 93.20 \\
\hline $\mathrm{Fe}_{3} \mathrm{O}_{4} @ \mathrm{AJPL}$ & 19.83 & 99.15 & 19.12 & 95.61 & 14.62 & 73.11 \\
\hline
\end{tabular}

$\mathrm{OH}$. These results are inconsistent with the ones reported by Pan et al. [48] and De Marco et al. [49].

3.2.3. Effect of Contact Time. The impact of the contact time on the MG adsorption by $\mathrm{Fe}_{3} \mathrm{O}_{4} @ \mathrm{AJPL}$ was achieved over the time interval of 5-240 min under fixed conditions (MG: $20 \mathrm{mg} / \mathrm{L}, \mathrm{pH}: 7$, temperature: $25^{\circ} \mathrm{C}$ dose: $50 \mathrm{mg}$, and agitation: $100 \mathrm{rpm}$ ) (Figure 5(b)). At an initial period of $15 \mathrm{~min}$, the adsorption rate was high with $R_{\mathrm{e}}(\%)$ and $q_{\mathrm{e}}$ values of $85.7 \%$ and $17.14 \mathrm{mg} / \mathrm{g}$, respectively. The initial rapid rate may indicate the existence of available active sites on the $\mathrm{Fe}_{3} \mathrm{O}_{4} @ \mathrm{AJPL}$ surface. After $15 \mathrm{~min}$, the adsorption was gradually increased with time, reaching the equilibrium, after $120 \mathrm{~min}$, at which the $q_{\mathrm{e}}$ and $R_{\mathrm{e}}(\%)$ were $18.32 \mathrm{mg} / \mathrm{g}$ and $91.6 \%$ at $120 \mathrm{~min}$, respectively. Thus, the optimized equilibrium time for the work was $120 \mathrm{~min}$. Compared with the literature, this equilibrium time is better than the ones previously reported by Pan et al. [48] and Gao et al. [50].

3.2.4. Effect of Dosage. The impact of the adsorbent dosage on the removal efficiency and adsorption capacity was tested in the range $10-100 \mathrm{mg}$ under the following conditions: MG: $20 \mathrm{mg} / \mathrm{L}, \mathrm{pH}: 7$, contact time: $120 \mathrm{~min}$, agitation: $100 \mathrm{rpm}$, and temperature: $25^{\circ} \mathrm{C}$. As shown in Figure 5(c), the $R_{\mathrm{e}}$ (\%) value was slightly improved from $94.3 \%$ to $99.1 \%$ with the gradual rise in the amount of $\mathrm{Fe}_{3} \mathrm{O}_{4} @ \mathrm{AJPL}$ adsorbent from 10 to $50 \mathrm{mg}$; however, the capacity $\left(q_{\mathrm{e}}\right)$ was reduced. These results can be assigned to increased active sites at a 


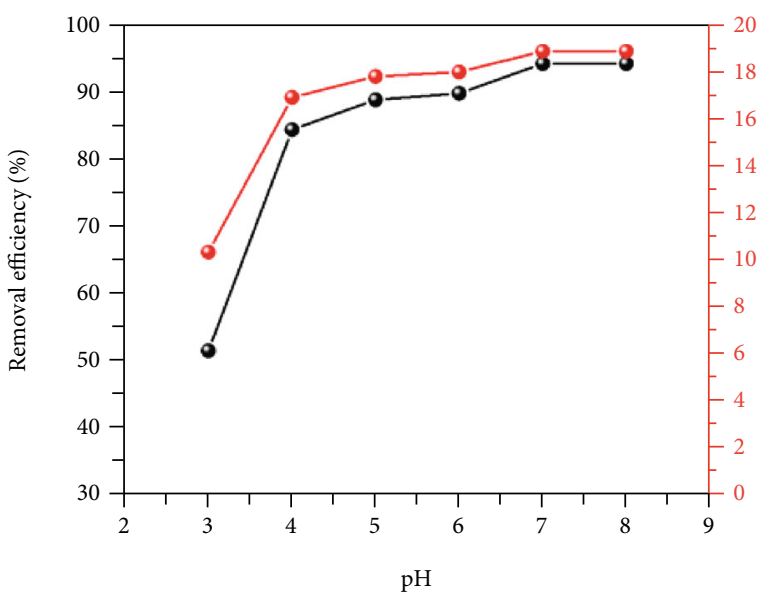

(a)

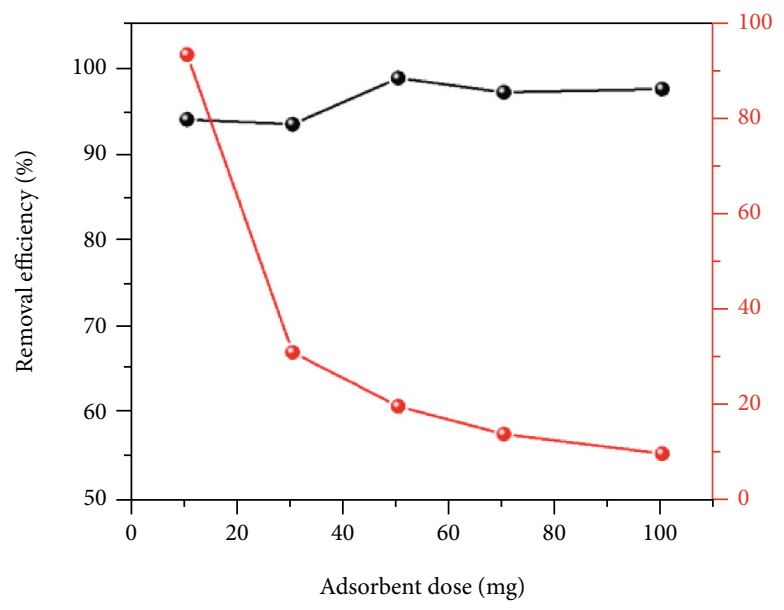

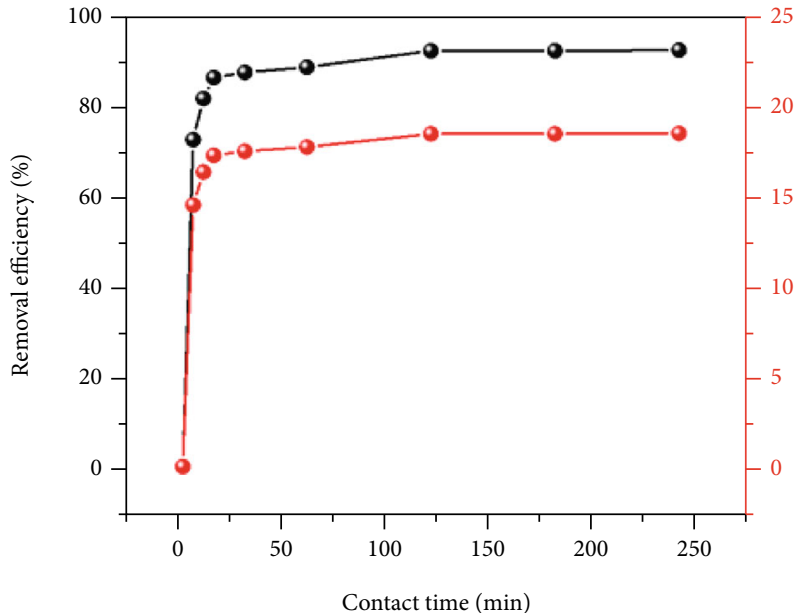

(b)

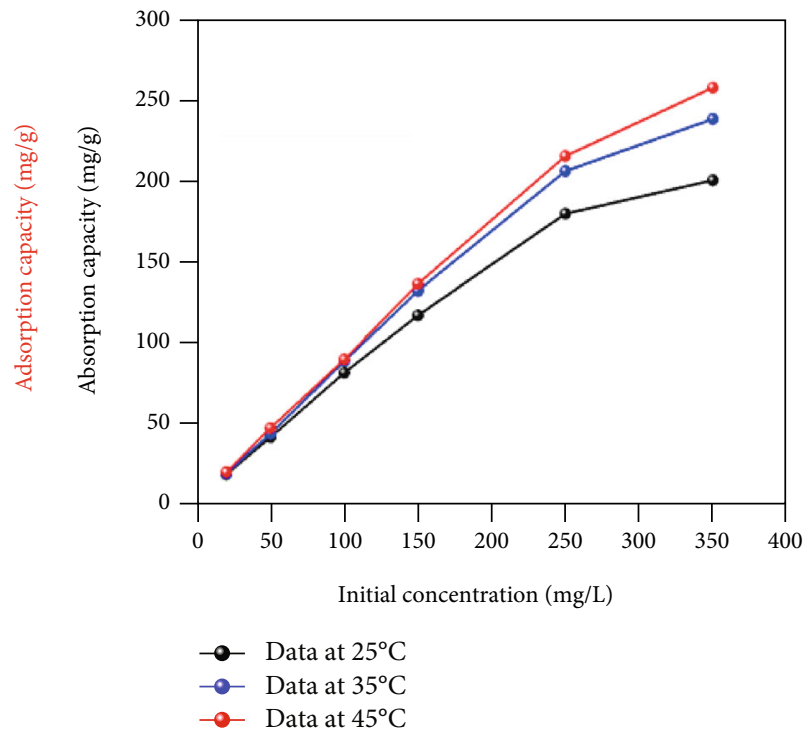

(d)

Figure 5: (a) Effect of $\mathrm{pH}$ value (conditions: $\mathrm{MG}-20 \mathrm{mg} / \mathrm{L}$, time-24h, $\mathrm{Fe}_{3} \mathrm{O}_{4} @ \mathrm{AJPAL}-50 \mathrm{mg}$, temperature-25 $5^{\circ}$, and agitation-100 rpm), (b) contact time (conditions: $\mathrm{MG}-20 \mathrm{mg} / \mathrm{L}, \mathrm{pH}-7, \mathrm{Fe}_{3} \mathrm{O}_{4} @ \mathrm{AJPAL}-50 \mathrm{mg}$, agitation-100 rpm, and temperature $-25^{\circ} \mathrm{C}$ ), (c) adsorbent dose (conditions: $\mathrm{MG}-20 \mathrm{mg} / \mathrm{L}, \mathrm{pH}-7$, time $-120 \mathrm{~min}$, temperature $-25^{\circ} \mathrm{C}$, and agitation-100 rpm), and (d) initial MG concentration (conditions: time-120, $\mathrm{Fe}_{3} \mathrm{O}_{4} @ \mathrm{AJPAL}-50 \mathrm{mg}, \mathrm{pH}-7$, temperature $-25^{\circ} \mathrm{C}$, and agitation-100 rpm) on the adsorption of MG on $\mathrm{Fe}_{3} \mathrm{O}_{4} @ \mathrm{AJPAL}$.

high adsorbent dose [51, 52]. However, no significant increase in the adsorption efficiency above the $50 \mathrm{mg}$ dose was observed. Moreover, the drop in the adsorption capacity is due to the aggregation events at a high dosage which lead to a decrease in the total surface area of the $\mathrm{Fe}_{3} \mathrm{O}_{4} @ \mathrm{JPL}$ adsorbent. These outcomes are consistent with the results of the literature reported in [53]. As a result, under the examined condition, the optimal adsorbent dose was $50 \mathrm{mg}$.

3.2.5. Effect of Initial Concentration and Temperatures. The adsorption capacities of the $\mathrm{Fe}_{3} \mathrm{O}_{4} @ \mathrm{AJPL}$ adsorbent at different initial MG concentrations $(20-350 \mathrm{mg} / \mathrm{L}$ ) and temperatures $\left(25,35\right.$, and $\left.45^{\circ} \mathrm{C}\right)$ were also studied, keeping other factors (time: $120 \mathrm{~min}, \mathrm{pH}$ : 7 , dose: $50 \mathrm{mg}$, and agitation:
$100 \mathrm{rpm}$ ) as given in Figure 5(d). The outcomes show that the adsorbed amount of MG dye by $\mathrm{Fe}_{3} \mathrm{O}_{4} @ \mathrm{AJPL}$ was linearly increased while the initial MG concentration increased, e.g., as $C_{0}$ was augmented from 20 to $350 \mathrm{mg} / \mathrm{L}$, the adsorption capacity improved from 18.5 to $201.2 \mathrm{mg} / \mathrm{g}$ at $25^{\circ} \mathrm{C}$. Such results can be ascribed to the increment in the driving force of the adsorbate concentration, resulting in a high diffusion rate of the MG dye from the liquid phase to the solid phase. At the higher $C_{\mathrm{o}}$ and at $45^{\circ} \mathrm{C}$, the archived $q_{\mathrm{e}}$ value was $258.6 \mathrm{mg} / \mathrm{g}$. Also, the adsorption capacity was increased from 18.5 to $20 \mathrm{mg} / \mathrm{g}$ with increasing temperature from $25^{\circ} \mathrm{C}$ to $45^{\circ} \mathrm{C}$ at $20 \mathrm{mg} / \mathrm{L}$. This increase in adsorption capacity is possibly due to diffusion enhancement of MG molecules to the surface and pores of $\mathrm{Fe}_{3} \mathrm{O}_{4} @ \mathrm{AJPL}$ which is driven by 


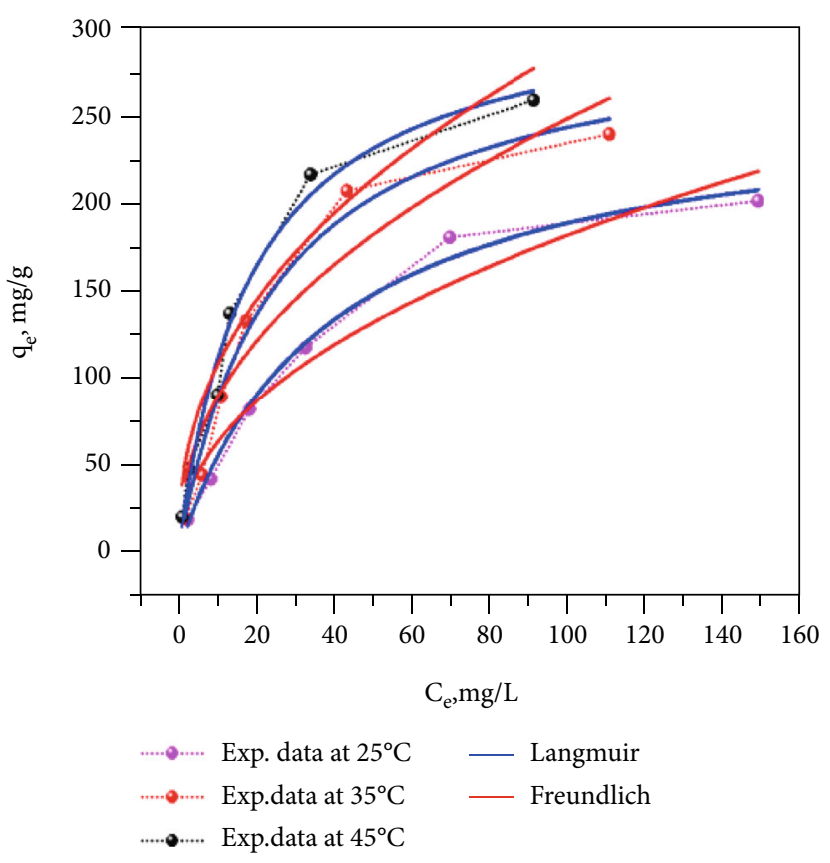

(a)

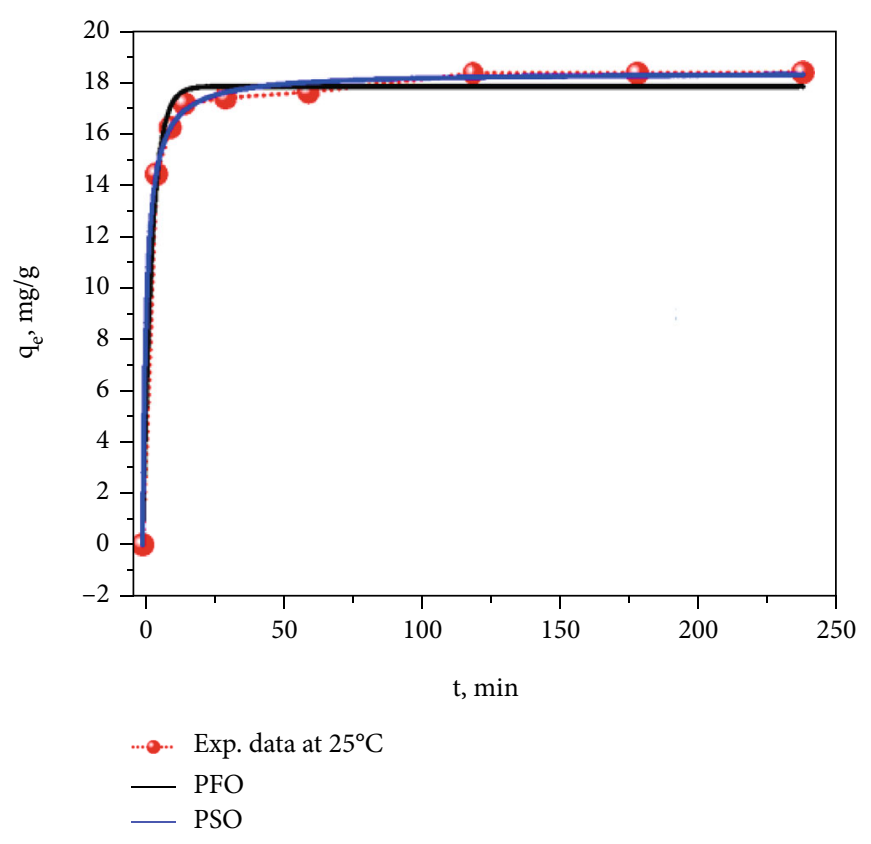

(b)

Figure 6: (a) Nonlinear adsorption isotherm at different temperature (conditions: MG-20-350 mg/L, time-120 min, $\mathrm{Fe}_{3} \mathrm{O}_{4} @ \mathrm{AJPAL}-50 \mathrm{mg}, \mathrm{pH}-7$, and agitation-100 rpm) and (b) nonlinear kinetic models for $\mathrm{MG}$ adsorption by $\mathrm{Fe}_{3} \mathrm{O}_{4} @ \mathrm{AJPAL}$ (conditions: $\mathrm{MG}-20 \mathrm{mg} / \mathrm{L}$, time-120 min, $\mathrm{Fe}_{3} \mathrm{O}_{4} @ \mathrm{AJPAL}-50 \mathrm{mg}, \mathrm{pH}-7$, temperature $-25^{\circ} \mathrm{C}$, and agitation-100 rpm).

TABle 2: Langmuir and Freundlich isotherm models for MG adsorption on $\mathrm{Fe}_{3} \mathrm{O}_{4} @ \mathrm{AJPL}$ nanocomposite (conditions: $\mathrm{MG}-20-350 \mathrm{mg} / \mathrm{L}, \quad$ time-120 min, $\quad \mathrm{Fe}_{3} \mathrm{O}_{4} @ \mathrm{AJPAL}-50 \mathrm{mg}$, volume $-0.05 \mathrm{~L}$, and agitation-100 rpm).

\begin{tabular}{lccc}
\hline Model & \multicolumn{3}{c}{ MG dye } \\
& $298 \mathrm{~K}$ & $308 \mathrm{~K}$ & $318 \mathrm{~K}$ \\
\hline Langmuir & & & \\
$q_{\mathrm{m}}(\mathrm{mg} / \mathrm{g})$ & 260.8 & 302.7 & 318.3 \\
$K_{\mathrm{L}}(\mathrm{L} / \mathrm{mg})$ & 0.026 & 0.040 & 0.052 \\
$R_{\mathrm{L}}$ & 0.657 & 0.551 & 0.485 \\
$R^{2}$ & 0.989 & 0.980 & 0.980 \\
Freundlich & & & \\
$K_{\mathrm{f}}(\mathrm{mg} / \mathrm{g})(\mathrm{L} / \mathrm{mg})^{1 / n}$ & 21.67 & 31.65 & 39.91 \\
$R^{2}$ & 0.929 & 0.894 & 0.925 \\
\hline
\end{tabular}

elevated kinetic energy at higher temperature, thus suggesting an endothermic adsorption process. These outcomes are consistent with other studies for the removal of MG ions by organically modified clay [54] and Fe-Mg BACs [55].

\subsection{Adsorption Modeling}

3.3.1. Adsorption Isotherm. The adsorption isotherm studies were accomplished over a range of MG initial concentrations of $20-350 \mathrm{mg} / \mathrm{L}$ and at temperatures of 25,35 , and $45^{\circ} \mathrm{C}$, keeping the other factors constants (i.e., adsorbent dose: $50 \mathrm{mg}$, $\mathrm{pH}$ : 7, contact time: $120 \mathrm{~min}$, and agitation speed: $100 \mathrm{rpm})$. Nonlinear isotherm adsorption models such as Langmuir (Equation (4)) [56] and Freundlich (Equa- tion (5)) [57] were applied to describe the behavior of the MG adsorption onto $\mathrm{Fe}_{3} \mathrm{O}_{4} @ \mathrm{AJPL}$.

$$
\begin{aligned}
& q_{\mathrm{e}}=\frac{q_{\mathrm{m}} K_{\mathrm{L}} C_{\mathrm{e}}}{1+K_{\mathrm{L}} C_{\mathrm{e}}}, \\
& q_{\mathrm{e}}=K_{\mathrm{F}} C_{\mathrm{e}}^{1 / n},
\end{aligned}
$$

where $q_{\mathrm{m}}$ is the maximum adsorption capacity (mg/g), $n$ is the adsorption intensity, $K_{\mathrm{F}}$ is the Freundlich isotherm constants, and $K_{\mathrm{L}}$ is the Langmuir constant. According to the isotherm data shown in Figure 6(a) and Table 2, it is clear that the Langmuir model $\left(R^{2}=0.989\right)$ provided a better fit than the Freundlich one $\left(R^{2}=0.929\right)$, suggesting monolayer coverage. The adsorbent capacity corresponding to the maximum monolayer coverage $\left(q_{\mathrm{m}}, \mathrm{mg} / \mathrm{g}\right)$ was $318.3 \mathrm{mg} / \mathrm{g}$ at $45^{\circ} \mathrm{C}$. The separation factor $\left(R_{\mathrm{L}}\right)$ values during the work were found in favorable adsorption $(<1)$ (i.e., 0.026, 0.040, and 0.052 at 298,308 , and $318 \mathrm{~K}$ ). Moreover, the increase in the values of the $K_{\mathrm{F}}$ and $K_{\mathrm{L}}$ constants with temperature confirmed endothermic adsorption $[58,59]$.

3.3.2. Kinetic Adsorption. The adsorption mechanism was achieved using the nonlinear kinetic models and pseudofirst-order (PFO) and pseudo-second-order models described by the following equations:

$$
\begin{aligned}
& q_{\mathrm{t}}=q_{\mathrm{e}}\left(1-e^{-k_{1} t}\right), \\
& q_{\mathrm{t}}=\frac{q_{\mathrm{e}}^{2} k_{2} t}{1+q_{\mathrm{e}} k_{2} t},
\end{aligned}
$$


TABle 3: Kinetic model parameters for $\mathrm{MG}$ adsorption on $\mathrm{Fe}_{3} \mathrm{O}_{4} @ \mathrm{AJPL}$ (conditions: $\mathrm{MG}-20 \mathrm{mg} / \mathrm{L}$, time-120 min, $\mathrm{Fe}_{3} \mathrm{O}_{4} @ \mathrm{AJPAL}-50 \mathrm{mg}$, volume-0.05 L, temperature-25 $5^{\circ}$, and agitation-100 rpm).

\begin{tabular}{lcccccc}
\hline$C_{\mathrm{o}}(\mathrm{mg} / \mathrm{L})$ & $\begin{array}{c}q_{\mathrm{e}, \text { exp }} \\
(\mathrm{mg} / \mathrm{g})\end{array}$ & $\begin{array}{c}q_{\mathrm{e} 1, \mathrm{cal}} \\
(\mathrm{mg} / \mathrm{g})\end{array}$ & $K_{1}(1 / \mathrm{min})$ & $R^{2}$ & $\begin{array}{c}q_{\mathrm{e} 2, \mathrm{cal}} \\
(\mathrm{mg} / \mathrm{g})\end{array}$ & $\begin{array}{c}\text { Pseudo-second-order } \\
K_{2} \\
(\mathrm{~g} / \mathrm{mg}-\mathrm{min})\end{array}$ \\
\hline 20 & 18.35 & 17.80 & 0.308 & 0.991 & 18.36 & 0.040 \\
\hline
\end{tabular}

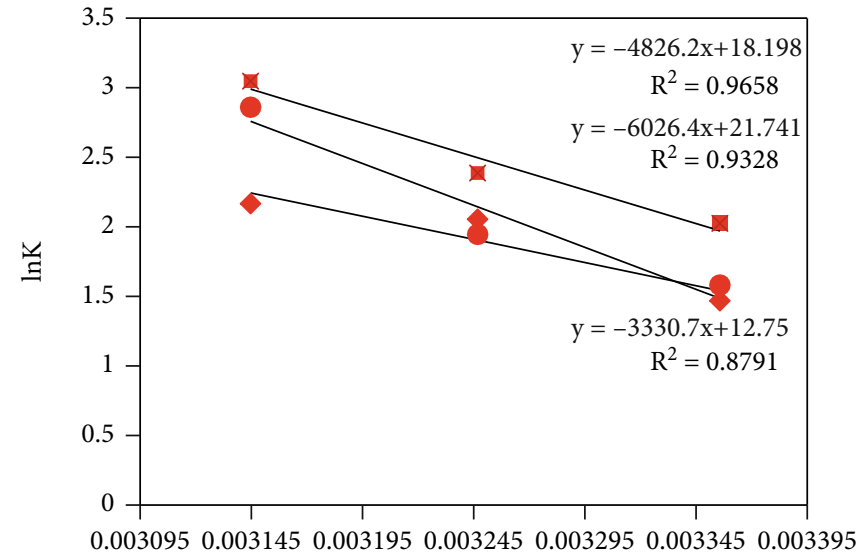

$1 / \mathrm{T}$

. $\mathrm{MGCi}=20 \mathrm{mg} / \mathrm{L}$

- $\mathrm{MGCi}=50 \mathrm{mg} / \mathrm{L}$

- $\mathrm{MGCi}=100 \mathrm{mg} / \mathrm{L}$

(a)

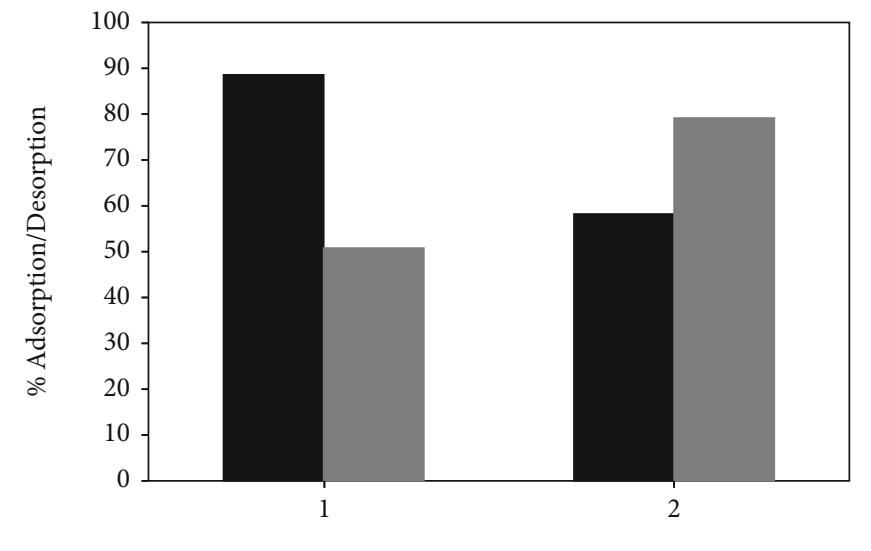

Number of cycle

\% Adsorption

\% Desorption

(c)

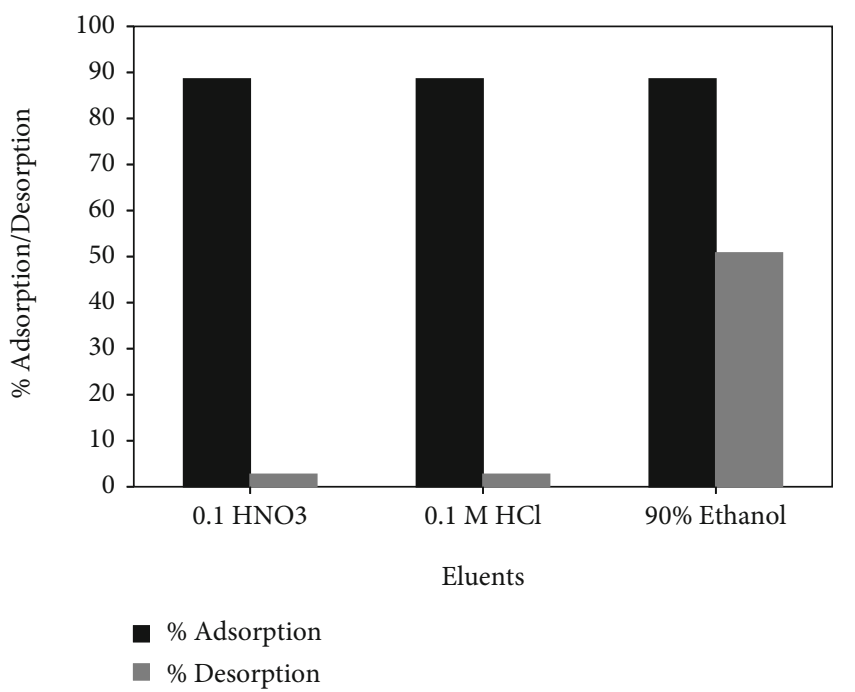

(b)

Figure 7: (a) Adsorption thermodynamics, (b) adsorption/desorption plot of MG dye from $\mathrm{Fe}_{3} \mathrm{O}_{4} @ \mathrm{AJPAL}$, and (c) recycling study (conditions: $\mathrm{MG}-20 \mathrm{mg} / \mathrm{L}$, time $-120 \mathrm{~min}, \mathrm{Fe}_{3} \mathrm{O}_{4} @ \mathrm{AJPAL}-50 \mathrm{mg}, \mathrm{pH}-7$, temperature $-25^{\circ} \mathrm{C}$, and agitation-100 rpm).

where $q_{\mathrm{t}}(\mathrm{mg} / \mathrm{g})$ is the adsorption capacity at time $t$ (min) and $k_{1}$ and $k_{2}$ are the rate constants of PFO and PSO, respectively. Figure 6(b) displays the kinetic plots for the $\mathrm{MG}$ adsorption onto $\mathrm{Fe}_{3} \mathrm{O}_{4} @ \mathrm{AJPL}$. It was observed that adsorption was fast in the first stage of the adsorption period $(20 \mathrm{~min})$, then slowly developed until equilibrium $(120 \mathrm{~min})$. The calculated kinetic parameters are given in Table 3. On the basis of $R^{2}$ values, the adsorption kinetics fit PSO $\left(R^{2}=0.998\right)$ better than the PFO $\left(R^{2}=0.991\right)$, suggesting that the adsorption of MG onto $\mathrm{Fe}_{3} \mathrm{O}_{4} @ \mathrm{AJPL}$ occurred by the chemisorption mechanism. Moreover, the $q_{\mathrm{e}}$, calculated according to the PSO kinetic model $\left(q_{\mathrm{e}}\right.$, cal $\left.=18.36 \mathrm{mg} / \mathrm{g}\right)$, was closer to the experimental 
TABle 4: Thermodynamic factors for adsorption of $\mathrm{MG}$ on $\mathrm{Fe}_{3} \mathrm{O}_{4} @ \mathrm{AJPL}$ (conditions: time-120 min, $\mathrm{Fe} \mathrm{O}_{4} @ \mathrm{AJPAL}-50 \mathrm{mg}$, volume $-0.05 \mathrm{~L}, \mathrm{pH}-7$, and agitation-100 rpm).

\begin{tabular}{|c|c|c|c|c|c|}
\hline \multirow{2}{*}{ Concentration MG dye } & \multirow{2}{*}{$\Delta H^{\circ}(\mathrm{kJ} / \mathrm{mol})$} & \multirow{2}{*}{$\Delta S^{\circ}(\mathrm{J} / \mathrm{mol} \cdot \mathrm{K})$} & \multicolumn{3}{|c|}{$(-) \Delta G^{\circ}(\mathrm{kJ} / \mathrm{mol})$} \\
\hline & & & $298 \mathrm{~K}$ & $308 \mathrm{~K}$ & $318 \mathrm{~K}$ \\
\hline 20 & 40.12 & 151.2 & 5.095 & 6.192 & 8.139 \\
\hline 50 & 50.10 & 180.7 & 3.998 & 5.065 & 7.646 \\
\hline 100 & 27.69 & 106.0 & 3.716 & 5.342 & 5.811 \\
\hline
\end{tabular}

TABLE 5: Comparison of the MG adsorption capacity of $\mathrm{Fe}_{3} \mathrm{O}_{4} @ \mathrm{AJPL}$ nanocomposite with other magnetic adsorbents.

\begin{tabular}{|c|c|c|c|}
\hline Adsorbent & Conditions & $q_{\mathrm{m}}(\mathrm{mg} / \mathrm{g})$ & Ref. \\
\hline $\mathrm{HNT}-\mathrm{Fe}_{3} \mathrm{O}_{4}$ & $C_{\mathrm{o}}: 40-120 \mathrm{mg} / \mathrm{L} ; \mathrm{T}: 298 \mathrm{~K} ; \mathrm{pH}: 8$; time: $240 \mathrm{~min}$; dose: $150 \mathrm{mg}$ & 44.25 & [49] \\
\hline A litchi peel-based magnetic & $C_{\mathrm{o}}: 150 \mathrm{mg} / \mathrm{L} ; \mathrm{pH}: 6 ; \mathrm{T}: 298 \mathrm{~K}$; dose: $5.14 \mathrm{~g} / \mathrm{L}$; time: $66.69 \mathrm{~min}$ & 70.42 & [66] \\
\hline $\mathrm{PDA} / \mathrm{CS} / \mathrm{Fe}_{3} \mathrm{O}_{4}$ & $C_{\mathrm{o}}: 5-200 \mathrm{mg} / \mathrm{L} ; \mathrm{T}: 303 \mathrm{~K} ; \mathrm{pH}: 8$; time: $40 \mathrm{~min}$; dose: $100 \mathrm{mg}$ & 60.97 & {$[67]$} \\
\hline Magnetic pectin-Chlorella vulgaris & $C_{\mathrm{o}}: 5-100 \mathrm{mg} / \mathrm{L} ; \mathrm{T}: 303 \mathrm{~K}$; dose: $50 \mathrm{mg}$; time: $30 \mathrm{~min}$ & 247.2 & {$[68]$} \\
\hline 3-MPA@PMNPs & $C_{\mathrm{o}}: 25 \mathrm{mg} / \mathrm{L} ; \mathrm{T}: 298 \mathrm{~K} ; \mathrm{pH}: 6$; time: $120 \mathrm{~min}$; dose: $500 \mathrm{mg}$ & 81.2 & [69] \\
\hline $\mathrm{Fe}_{3} \mathrm{O}_{4} @ \mathrm{AMCA}-\mathrm{MIL}-53(\mathrm{Al})$ & $C_{\mathrm{o}}: 25-400 \mathrm{mg} / \mathrm{L} ; \mathrm{T}: 298 \mathrm{~K} ; \mathrm{pH}: 6.8$; time: $210 \mathrm{~min}$; dose: $20 \mathrm{mg}$ & 262.52 & {$[70]$} \\
\hline $\mathrm{Fe}_{3} \mathrm{O}_{4} @ \mathrm{AJPL}$ & $C_{\mathrm{o}}: 25-350 \mathrm{mg} / \mathrm{L} ; \mathrm{T}: 318 \mathrm{~K} ; \mathrm{pH}: 7$; time: $120 \mathrm{~min}$; dose: $50 \mathrm{mg}$ & 318.3 & This study \\
\hline
\end{tabular}

value $\left(q_{\mathrm{e}}\right.$ exp $\left.=18.35 \mathrm{mg} / \mathrm{g}\right)$, supporting the PSO model. Similar trends have been reported by other adsorbents $[60,61]$.

3.3.3. Adsorption Thermodynamics. The adsorption thermodynamic factors such as the Gibbs free energy $\left(\Delta G^{\circ}\right)$, entropy $\left(\Delta S^{\circ}\right)$, and enthalpy $\left(\Delta H^{\circ}\right)$ for the removal of the MG dye onto the $\mathrm{Fe}_{3} \mathrm{O}_{4} @ \mathrm{AJPL}$ nanocomposite were calculated using Equation (8) and the van't Hoff equation (Equation (9)) [62]:

$$
\begin{gathered}
\Delta G^{\circ}=-R T \ln K_{\mathrm{c}}, \\
\ln K_{\mathrm{c}}=-\frac{\Delta H^{0}}{R T}+\frac{\Delta S^{0}}{R},
\end{gathered}
$$

where $R$ is gas constant $(8.314 \mathrm{~J} / \mathrm{mol} \cdot \mathrm{K})$ and $K_{\mathrm{c}}$ represents the equilibrium constant and its equal $q_{\mathrm{e}} / c_{\mathrm{e}}$ [63]; the other notations have the same meaning as above.

Figure 7 (a) and Table 4 summarize the data obtained. The value of $\Delta G^{\circ}$ obtained was negative, indicating that the adsorption of $\mathrm{MG}$ onto $\mathrm{Fe}_{3} \mathrm{O}_{4} @ \mathrm{AJPL}$ is spontaneous. The positive values of $\Delta H^{\circ}$ and $\Delta S^{\circ}$ indicate the endothermic process and increase in randomness during the adsorption process, respectively. The temperature-dependent $\Delta G^{\circ}$ revealed favorable adsorption at higher temperature; however, the effect of the initial concentration of MG suggests better adsorption at a lower concentration. Additionally, the value of $\Delta H^{\circ}>40 \mathrm{~kJ} \mathrm{~mol}^{-1}$ at a low concentration means that the mechanism of MG adsorption is chemisorption. Therefore, at the examined adsorption conditions, the obtained $\Delta G^{\circ}$ and $\Delta H^{\circ}$ values suggest physical and chemical adsorption mechanisms, respectively [64]. Similar trends have been reported by Arabkhani et al. for the removal of MG using the GO/MMT polymer nanocomposite [65].

3.4. Adsorption Mechanism. Figure 1 shows the stepwise preparation of the adsorbent $\mathrm{Fe}_{3} \mathrm{O}_{4} @ \mathrm{AJPL}$ and the proposed adsorption mechanism. According to the FTIR spectrum, after MG dye adsorption on the $\mathrm{Fe}_{3} \mathrm{O}_{4} @ \mathrm{AJPL}$ nanocomposite, there was a decrease and shift in the peak intensities of the functional groups. it was observed that the peaks at $3320 \mathrm{~cm}^{-1}, 1731 \mathrm{~cm}^{-1}$, and $1026 \mathrm{~cm}^{-1}$ decrease and shift to $3329 \mathrm{~cm}^{-1}, 1721 \mathrm{~cm}^{-1}$, and $1023 \mathrm{~cm}^{-1}$, respectively, due to adsorptive interaction between the $\mathrm{MG}$ dye and the $\mathrm{COOH}$, $\mathrm{OH}$, and $\mathrm{C}-\mathrm{O}-\mathrm{C}$ groups on the $\mathrm{Fe}_{3} \mathrm{O}_{4} @ \mathrm{AJPL}$ surface by different mechanisms such as hydrogen bonding, $\pi-\pi$ stacking, and electrostatic interaction. The nonlinear isotherm and kinetic adsorption studies exhibited a better fit to PSO kinetic and Langmuir isotherm models, indicating chemisorption adsorption. Additionally, the weak desorption efficiency of $\mathrm{MG}$ from the $\mathrm{Fe}_{3} \mathrm{O}_{4} @ \mathrm{AJPL}$ surface confirms the chemisorption mechanism. It was observed that adsorption of $\mathrm{MG}$ onto $\mathrm{Fe}_{3} \mathrm{O}_{4} @ \mathrm{AJPL}$ was fast in the first stage of the adsorption period (15 min) then slowly developed until equilibrium (120 min). The initial rapid rate may indicate existence of available active sites on the $\mathrm{Fe}_{3} \mathrm{O}_{4} @ \mathrm{AJPL}$ surface. Furthermore, the data indicate that more than $85.7 \%$ of MG molecules were adsorbed in the first stage, supporting the chemical adsorption mechanism. However, the first stage cannot be recognized, and the slow rate in the second adsorption phase suggests a physical mechanism, which is possibly controlled by the diffusion process. On the other hand, the thermodynamic data support the physisorption mechanism. Therefore, it could be concluded that the MG adsorption on $\mathrm{Fe}_{3} \mathrm{O}_{4} @ \mathrm{AJPL}$ occurred by physical adsorption together with the chemisorption process. The EDX analysis clearly shows a new peak of nitrogen along with the peaks of elements of the $\mathrm{Fe}_{3} \mathrm{O}_{4} @ \mathrm{AJPL}$ nanocomposite, indicating MG adsorption onto the whole surface of the $\mathrm{Fe}_{3} \mathrm{O}_{4} @ \mathrm{AJPL}$ adsorbent.

3.5. Comparative Performance of $\mathrm{Fe}_{3} \mathrm{O}_{4} @ A J P L$ with Other Adsorbents. For comparative purposes, the maximum 
adsorption capacity, $q_{\mathrm{m}}$, of some other adsorbents reported in the literature for the MG uptake are given in Table 5 $[49,66-70]$; the adsorption conditions are also tabulated for easy comparison. Obviously, the $q_{\mathrm{m}}$ value of $\mathrm{Fe}_{3} \mathrm{O}_{4} @ \mathrm{AJPL}(318.3 \mathrm{mg} / \mathrm{g})$ for $\mathrm{MG}$ adsorption is greater than the other listed magnetic nanocomposite adsorbents. The difference in the efficiencies of various adsorbents is due to the diversity in the adsorbent's structures and morphologies. Hence, the characteristics and performance of the investigated adsorbent, $\mathrm{Fe}_{3} \mathrm{O}_{4} @ \mathrm{AJPL}$, support its being appropriate as a potential adsorbent for the removal of cationic pollutants such as MG from polluted aqueous systems.

3.6. Desorption and Reusability Studies. To recover the MG dye from the $\mathrm{Fe}_{3} \mathrm{O}_{4} @ \mathrm{AJPL}$ nanocomposite, three eluents, $0.1 \mathrm{M} \mathrm{HCl}, 0.1 \mathrm{M} \mathrm{HNO}_{3}$, and ethanol (90\%), were used (Figure 7(b)). From the results, it was observed that the recovery performance of ethanol was the highest $(50.77 \%)$, while the acidic eluents $\left(\mathrm{HCl}\right.$ and $\left.\mathrm{HNO}_{3}\right)$ used showed only negligible efficiencies toward $\mathrm{MG}$ elution. The low recovery efficiency of $\mathrm{MG}$ from the $\mathrm{Fe}_{3} \mathrm{O}_{4} @ \mathrm{AJPL}$ nanocomposite surface using ethanol indicates that most of the $\mathrm{MG}$ adsorption was probably by chemisorption. The outcomes of the kinetic and isotherm adsorption confirm the chemical adsorption mechanisms. The regeneration efficiency after two cycles was also examined. The result revealed that the adsorption efficiency of the MG dye on $\mathrm{Fe}_{3} \mathrm{O}_{4} @ \mathrm{AJPL}$ was decreased from $89.5 \%$ to $58.2 \%$ as well as in the recovery percentage mostly due to incomplete desorption in the first cycle of the adsorption-desorption process as well as possible destruction of some active sites on the $\mathrm{Fe}_{3} \mathrm{O}_{4} @ \mathrm{AJPL}$ surface.

\section{Conclusion}

In summary, a new magnetic nanocomposite $\left(\mathrm{Fe}_{3} \mathrm{O}_{4} @ \mathrm{AJPL}\right)$ adsorbent was successfully synthesized via chemical activation of JPL and in situ coprecipitation with $\mathrm{Fe}_{3} \mathrm{O}_{4}$. The $\mathrm{Fe}_{3} \mathrm{O}_{4} @ \mathrm{AJPL}$ nanocomposite was applied for the removal of the MG dye from aqueous solutions. The $\mathrm{Fe}_{3} \mathrm{O}_{4} @ \mathrm{AJPL}$ nanocomposite was analyzed using different analytical techniques, and the results confirmed that the $\mathrm{Fe}_{3} \mathrm{O}_{4} @ \mathrm{AJPL}$ nanocomposite was successfully synthesized. The surface area of the $\mathrm{Fe}_{3} \mathrm{O}_{4} @ \mathrm{AJPL}$ nanocomposite was identified via BET analysis, and it is found to be $38.44 \mathrm{~m}^{2} / \mathrm{g}$. The $\mathrm{Fe}_{3} \mathrm{O}_{4} @ \mathrm{AJPL}$ nanocomposite was tested to thoroughly clarify the influences of the factors on the adsorption of $\mathrm{MG}$ onto $\mathrm{Fe}_{3} \mathrm{O}_{4} @ \mathrm{AJPL}$. The optimized adsorption factors were found to be $\mathrm{pH}: 7$, contact time: $120 \mathrm{~min}$, adsorbent dose: $50 \mathrm{mg}$, temperature: $45^{\circ} \mathrm{C}$, and initial $\mathrm{MG}$ concentration: $150 \mathrm{mg} / \mathrm{L}$. The adsorption kinetic and isotherm were revealed to be a better fit to the PSO kinetic and Langmuir isotherm models. The maximum monolayer adsorption capacity was $318.3 \mathrm{mg} / \mathrm{g}$ at $45^{\circ} \mathrm{C}$, which was greater than magnetic nanocomposite adsorbents reported previously. The thermodynamic studies indicated that the adsorption of $\mathrm{MG}$ onto $\mathrm{Fe}_{3} \mathrm{O}_{4} @ \mathrm{AJPL}$ is a spontaneous and endothermic process. The interaction between the $\mathrm{Fe}_{3} \mathrm{O}_{4} @ \mathrm{AJPL}$ nano- composite and the MG dye occurred by chemisorption and physisorption that can be achieved by H-bonding, $\pi-\pi$ interactions, and electrostatic attractions. The recovery results indicated that ethanol was the best eluent among the all the tested eluents. Overall, it could be concluded that the prepared $\mathrm{Fe}_{3} \mathrm{O}_{4} @ \mathrm{AJPL}$ adsorbent will be a promising adsorbent for the elimination of $\mathrm{MG}$ dye from aqueous solutions

\section{Data Availability}

Anyone who wants to request research article data can contact me directly via the following email: aalorabi@bu.edu.sa, Chemistry Department, College of Science, Al Baha University.

\section{Conflicts of Interest}

There are no conflicts to declare.

\section{Acknowledgments}

We gratefully acknowledge the financial support by Albaha University (Project No. 1441/3) and are grateful to the Scientific Research Deanship.

\section{References}

[1] R. Bagheri, M. Ghaedi, A. Asfaram, E. Alipanahpour Dil, and H. Javadian, "RSM-CCD design of malachite green adsorption onto activated carbon with multimodal pore size distribution prepared from Amygdalus scoparia: Kinetic and isotherm studies," Polyhedron, vol. 171, pp. 464-472, 2019.

[2] F. Du, L. Sun, Z. Huang et al., "Electrospun reduced graphene oxide/ $\mathrm{TiO}_{2} /$ poly(acrylonitrile- co -maleic acid) composite nanofibers for efficient adsorption and photocatalytic removal of malachite green and leucomalachite green," Chemosphere, vol. 239, article 124764, 2020.

[3] R. Gopinathan, J. Kanhere, and J. Banerjee, "Effect of malachite green toxicity on non target soil organisms," Chemosphere, vol. 120, pp. 637-644, 2015.

[4] A. A. Ahmad, M. A. Ahmad, N. K. E. M. Yahaya, and J. Karim, "Adsorption of malachite green by activated carbon derived from gasified Hevea brasiliensis root," Arabian Journal of Chemistry, vol. 14, no. 4, article 103104, 2021.

[5] H. Zhang, F. Zhang, and Q. Huang, "Highly effective removal of malachite green from aqueous solution by hydrochar derived from phycocyanin-extracted algal bloom residues through hydrothermal carbonization," RSC Advances, vol. 7, no. 10, pp. 5790-5799, 2017.

[6] M. Reza Shirzad Kebria and A. Rahimpour, "Membrane distillation: basics, advances, and applications," Advances in Membrane Technologies, vol. 67, 2020.

[7] S. P. Vinay, F. A. Alharthi, Udayabhanu, A. Alsalme, and G. Nagaraju, "Hydrothermal synthesis of Ag/rGO@CTFE nanocomposite as a promising photocatalyst for degradation action," Journal of Molecular Structure, vol. 1228, article 129722, 2021.

[8] B. Krishnakumar, A. Alsalme, F. A. Alharthi et al., "Synthesis, characterization of gelatin assisted $\mathrm{ZnO}$ and its effective 
utilization of toxic azo dye degradation under direct sunlight," Optical Materials, vol. 113, article 110854, 2021.

[9] I. Oller, S. Malato, and J. A. Sánchez-Pérez, "Combination of Advanced Oxidation Processes and biological treatments for wastewater decontamination-A review," Science of the Total Environment, vol. 409, no. 20, pp. 4141-4166, 2011.

[10] C. A. Martínez-Huitle and E. Brillas, "Decontamination of wastewaters containing synthetic organic dyes by electrochemical methods: a general review," Applied Catalysis B: Environmental, vol. 87, no. 3-4, pp. 105-145, 2009.

[11] J. Labanda, J. Sabaté, and J. Llorens, "Modeling of the dynamic adsorption of an anionic dye through ion-exchange membrane adsorber," Journal of Membrane Science, vol. 340, no. 1-2, pp. 234-240, 2009.

[12] A. A. Alqadami, M. A. Khan, M. R. Siddiqui, and Z. A. Alothman, "Development of citric anhydride anchored mesoporous MOF through post synthesis modification to sequester potentially toxic lead (II) from water," Microporous and Mesoporous Materials, vol. 261, pp. 198-206, 2018.

[13] A. A. Alqadami, M. A. Khan, M. R. Siddiqui, Z. A. Alothman, and S. Sumbul, "A facile approach to develop industrial waste encapsulated cryogenic alginate beads to sequester toxic bivalent heavy metals," Journal of King Saud University - Science, vol. 32, no. 2, pp. 1444-1450, 2020.

[14] M. Alsuhybani, A. Alshahrani, M. Algamdi, A. A. Al-Kahtani, and A. A. Alqadami, "Highly efficient removal of $\mathrm{Pb}$ (II) from aqueous systems using a new nanocomposite: adsorption, isotherm, kinetic and mechanism studies," Journal of Molecular Liquids, vol. 301, article 112393, 2019.

[15] A. Q. Alorabi, M. Shamshi Hassan, and M. Azizi, " $\mathrm{Fe}_{3} \mathrm{O}_{4^{-}}$ $\mathrm{CuO}$-activated carbon composite as an efficient adsorbent for bromophenol blue dye removal from aqueous solutions," Arabian Journal of Chemistry, vol. 13, no. 11, pp. 8080-8091, 2020.

[16] W. A. Amer, M. M. Omran, A. F. Rehab, and M. M. Ayad, "Acid green crystal-based in situ synthesis of polyaniline hollow nanotubes for the adsorption of anionic and cationic dyes," RSC Advances, vol. 8, no. 40, pp. 22536-22545, 2018.

[17] G. Crini, G. Torri, E. Lichtfouse, G. Z. Kyzas, L. D. Wilson, and N. Morin-Crini, "Dye removal by biosorption using crosslinked chitosan-based hydrogels," Environmental Chemistry Letters, vol. 17, no. 4, pp. 1645-1666, 2019.

[18] Ş. Parlayici, "Alginate-coated perlite beads for the efficient removal of methylene blue, malachite green, and methyl violet from aqueous solutions: kinetic, thermodynamic, and equilibrium studies," Journal of Analytical Science and Technology, vol. 10, no. 1, p. 4, 2019.

[19] R. Ben Arfi, S. Karoui, K. Mougin, and A. Ghorbal, "Adsorptive removal of cationic and anionic dyes from aqueous solution by utilizing almond shell as bioadsorbent," EuroMediterranean Journal for Environmental Integration, vol. 2, no. 1, pp. 1-13, 2017.

[20] B. H. Hameed and A. A. Ahmad, "Batch adsorption of methylene blue from aqueous solution by garlic peel, an agricultural waste biomass," Journal of Hazardous Materials, vol. 164, no. 2-3, pp. 870-875, 2009.

[21] L. S. Oliveira, A. S. Franca, T. M. Alves, and S. D. F. Rocha, "Evaluation of untreated coffee husks as potential biosorbents for treatment of dye contaminated waters," Journal of Hazardous Materials, vol. 155, no. 3, pp. 507-512, 2008.

[22] H. Tahir, M. Sultan, N. Akhtar, U. Hameed, and T. Abid, "Application of natural and modified sugar cane bagasse for the removal of dye from aqueous solution," Journal of Saudi Chemical Society, vol. 20, pp. S115-S121, 2016.

[23] A. A. Oyekanmi, A. Ahmad, K. Hossain, and M. Rafatullah, "Statistical optimization for adsorption of rhodamine B dye from aqueous solutions," Journal of Molecular Liquids, vol. 281, pp. 48-58, 2019.

[24] V. S. Munagapati, V. Yarramuthi, Y. Kim, K. M. Lee, and D.S. Kim, "Removal of anionic dyes (reactive black 5 and Congo red) from aqueous solutions using banana peel powder as an adsorbent," Ecotoxicology and Environmental Safety, vol. 148, pp. 601-607, 2018.

[25] P. Janoš, H. Buchtová, and M. Rýznarová, "Sorption of dyes from aqueous solutions onto fly ash," Water Research, vol. 37, no. 20, pp. 4938-4944, 2003.

[26] O. Hamdaoui, F. Saoudi, M. Chiha, and E. Naffrechoux, "Sorption of malachite green by a novel sorbent, dead leaves of plane tree: equilibrium and kinetic modeling," Chemical Engineering Journal, vol. 143, no. 1-3, pp. 73-84, 2008.

[27] N. Gupta, A. K. Kushwaha, and M. C. Chattopadhyaya, "Adsorption studies of cationic dyes onto Ashoka (Saraca asoca) leaf powder," Journal of the Taiwan Institute of Chemical Engineers, vol. 43, no. 4, pp. 604-613, 2012.

[28] L. Bulgariu, L. B. Escudero, O. S. Bello et al., "The utilization of leaf-based adsorbents for dyes removal: a review," Journal of Molecular Liquids, vol. 276, pp. 728-747, 2019.

[29] H. S. al-Shehri, E. Almudaifer, A. Q. Alorabi, H. S. Alanazi, A. S. Alkorbi, and F. A. Alharthi, "Effective adsorption of crystal violet from aqueous solutions with effective adsorbent: equilibrium, mechanism studies and modeling analysis," Environmental Pollutants and Bioavailability, vol. 33, no. 1, pp. 214-226, 2021.

[30] M. D. Huff and J. W. Lee, "Biochar-surface oxygenation with hydrogen peroxide," Journal of Environmental Management, vol. 165, pp. 17-21, 2016.

[31] Y. Xue, B. Gao, Y. Yao et al., "Hydrogen peroxide modification enhances the ability of biochar (hydrochar) produced from hydrothermal carbonization of peanut hull to remove aqueous heavy metals: batch and column tests," Chemical Engineering Journal, vol. 200-202, pp. 673-680, 2012.

[32] A. A. Alqadami, M. Naushad, M. A. Abdalla, M. R. Khan, and Z. A. Alothman, "Adsorptive removal of toxic dye using $\mathrm{Fe}_{3} \mathrm{O}_{4}$ -TSC nanocomposite: equilibrium, kinetic, and thermodynamic studies," Journal of Chemical \& Engineering Data, vol. 61, no. 11, pp. 3806-3813, 2016.

[33] M. Burits, K. Asres, and F. Bucar, "The antioxidant activity of the essential oils of Artemisia afra, Artemisia abyssinica and Juniperus procera," Phytotherapy Research, vol. 15, no. 2, pp. 103-108, 2001.

[34] M. Loizzo, R. Tundis, F. Conforti, A. Saab, G. Statti, and F. Menichini, "Comparative chemical composition, antioxidant and hypoglycaemic activities of Juniperus oxycedrus ssp. oxycedrus L. berry and wood oils from Lebanon," Food Chemistry, vol. 105, no. 2, pp. 572-578, 2007.

[35] B. Šarić-Kundalić, C. Dobeš, V. Klatte-Asselmeyer, and J. Saukel, "Ethnobotanical survey of traditionally used plants in human therapy of east, north and north-east Bosnia and Herzegovina," Journal of Ethnopharmacology, vol. 133, no. 3, pp. 1051-1076, 2011.

[36] M. Öztürk, İ. Tümen, A. Uğur, F. Aydoğmuş-Öztürk, and G. Topçu, "Evaluation of fruit extracts of six Turkish Juniperus species for their antioxidant, anticholinesterase and 
antimicrobial activities," Journal of the Science of Food and Agriculture, vol. 91, no. 5, pp. 867-876, 2011.

[37] B. S. Ndazi, S. Karlsson, J. V. Tesha, and C. W. Nyahumwa, "Chemical and physical modifications of rice husks for use as composite panels," Composites Part A: applied science and manufacturing, vol. 38, no. 3, pp. 925-935, 2007.

[38] K. Le Van and T. T. Luong Thi, “Activated carbon derived from rice husk by $\mathrm{NaOH}$ activation and its application in supercapacitor," Progress in Natural Science: Materials International, vol. 24, no. 3, pp. 191-198, 2014.

[39] E. H. Ibrahim, M. Kilany, H. A. Ghramh, K. A. Khan, and S. ul Islam, "Cellular proliferation/cytotoxicity and antimicrobial potentials of green synthesized silver nanoparticles (AgNPs) using Juniperus procera," Saudi Journal of Biological Sciences, vol. 26, no. 7, pp. 1689-1694, 2019.

[40] A. A. Alqadami, M. A. Khan, M. Otero, M. R. Siddiqui, B.H. Jeon, and K. M. Batoo, "A magnetic nanocomposite produced from camel bones for an efficient adsorption of toxic metals from water," Journal of Cleaner Production, vol. 178, pp. 293-304, 2018.

[41] M. A. Khan, A. A. Alqadami, M. Otero et al., "Heteroatomdoped magnetic hydrochar to remove post-transition and transition metals from water: synthesis, characterization, and adsorption studies," Chemosphere, vol. 218, pp. 1089-1099, 2019.

[42] A. Allafchian, Z. S. Mousavi, and S. S. Hosseini, "Application of cress seed musilage magnetic nanocomposites for removal of methylene blue dye from water," International Journal of Biological Macromolecules, vol. 136, pp. 199208, 2019.

[43] Q. Tang, X. Tang, Z. Li et al., "Zn(II) removal with Activated Firmiana Simplex Leaf: kinetics and equilibrium studies," Journal of Environmental Engineering, vol. 138, no. 2, pp. 190-199, 2012.

[44] A. Alqadami, M. Naushad, M. A. Abdalla, T. Ahamad, Z. Abdullah Alothman, and S. M. Alshehri, "Synthesis and characterization of $\mathrm{Fe}_{3} \mathrm{O}_{4} @$ TSC nanocomposite: highly efficient removal of toxic metal ions from aqueous medium," RSC advances, vol. 6, no. 27, pp. 22679-22689, 2016.

[45] G. Karthivashan, M. J. Masarudin, A. Umar Kura, F. Abas, and S. Fakurazi, "Optimization, formulation, and characterization of multiflavonoids-loaded flavanosome by bulk or sequential technique," International Journal of Nanomedicine, vol. 11, pp. 3417-3434, 2016.

[46] E. Ekmen, M. Bilici, E. Turan, U. Tamer, and A. Zengin, "Surface molecularly-imprinted magnetic nanoparticles coupled with SERS sensing platform for selective detection of malachite green," Sensors and Actuators B: Chemical, vol. 325, article 128787, 2020.

[47] A. Asfaram, M. Ghaedi, G. R. Ghezelbash et al., "Biosorption of malachite green by novel biosorbent Yarrowia lipolytica isf7: Application of response surface methodology," Journal of Molecular Liquids, vol. 214, pp. 249-258, 2016.

[48] X. Pan, G. Zuo, T. Su et al., "Polycarboxylic magnetic polydopamine sub-microspheres for effective adsorption of malachite green," Colloids and Surfaces A: Physicochemical and Engineering Aspects, vol. 560, pp. 106-113, 2019.

[49] C. De Marco, R. S. Mauler, T. S. Daitx et al., "Removal of malachite green dye from aqueous solutions by a magnetic adsorbent," Separation Science and Technology, vol. 55, no. 6, pp. 1089-1101, 2020.
[50] M. Gao, Z. Wang, C. Yang, J. Ning, Z. Zhou, and G. Li, "Novel magnetic graphene oxide decorated with persimmon tannins for efficient adsorption of malachite green from aqueous solutions," Colloids and Surfaces A: Physicochemical and Engineering Aspects, vol. 566, pp. 48-57, 2019.

[51] W. A. Amer, M. M. Omran, and M. M. Ayad, "Acid-free synthesis of polyaniline nanotubes for dual removal of organic dyes from aqueous solutions," Colloids and Surfaces A: Physicochemical and Engineering Aspects, vol. 562, pp. 203-212, 2019.

[52] M. Ghaedi, Z. Rozkhoosh, A. Asfaram, B. Mirtamizdoust, Z. Mahmoudi, and A. A. Bazrafshan, "Comparative studies on removal of erythrosine using $\mathrm{ZnS}$ and $\mathrm{AgOH}$ nanoparticles loaded on activated carbon as adsorbents: kinetic and isotherm studies of adsorption," Spectrochimica Acta Part A: Molecular and Biomolecular Spectroscopy, vol. 138, pp. 176-186, 2015.

[53] A. M. Aldawsari, I. H. Alsohaimi, A. A. Al-Kahtani, A. A. Alqadami, Z. E. Ali Abdalla, and E. A. M. Saleh, "Adsorptive performance of aminoterephthalic acid modified oxidized activated carbon for malachite green dye: mechanism, kinetic and thermodynamic studies," Separation Science and Technology, vol. 56, no. 5, pp. 835-846, 2021.

[54] S. Arellano-Cárdenas, S. López-Cortez, M. Cornejo-Mazón, and J. C. Mares-Gutiérrez, "Study of malachite green adsorption by organically modified clay using a batch method," Applied Surface Science, vol. 280, pp. 74-78, 2013.

[55] F. Guo, X. Jiang, X. Li, X. Jia, S. Liang, and L. Qian, “Synthesis of $\mathrm{MgO} / \mathrm{Fe}_{3} \mathrm{O}_{4}$ nanoparticles embedded activated carbon from biomass for high-efficient adsorption of malachite green," Materials Chemistry and Physics, vol. 240, article 122240, 2020.

[56] A. Wallis and M. F. Dollard, "Local and global factors in work stress - the Australian dairy farming examplar," Scandinavian Journal of Work, Environment and Health, vol. 34, no. 6, pp. 66-74, 2008.

[57] H. Freundlich, Über die adsorption in lösungen, vol. 57, no. 1, 1907Zeitschrift Für Physikalische Chemie, 1907.

[58] S. Agarwal, I. Tyagi, V. K. Gupta, S. Mashhadi, and M. Ghasemi, "Kinetics and thermodynamics of malachite green dye removal from aqueous phase using iron nanoparticles loaded on ash," Journal of Molecular Liquids, vol. 223, pp. 1340-1347, 2016.

[59] S. N. Jain, Z. Shaikh, V. S. Mane et al., "Nonlinear regression approach for acid dye remediation using activated adsorbent: kinetic, isotherm, thermodynamic and reusability studies," Microchemical Journal, vol. 148, pp. 605-615, 2019.

[60] H. Jayasantha Kumari, P. Krishnamoorthy, T. K. Arumugam, S. Radhakrishnan, and D. Vasudevan, "An efficient removal of crystal violet dye from waste water by adsorption onto TLAC/chitosan composite: a novel low cost adsorbent," International Journal of Biological Macromolecules, vol. 96, pp. 324-333, 2017.

[61] P. Arabkhani, H. Javadian, A. Asfaram, and M. Ateia, "Decorating graphene oxide with zeolitic imidazolate framework (ZIF-8) and pseudo-boehmite offers ultra-high adsorption capacity of diclofenac in hospital effluents," Chemosphere, vol. 271, article 129610, 2021.

[62] A. A. Alghamdi, A.-B. Al-Odayni, W. S. Saeed et al., "Adsorption of azo dye methyl orange from aqueous solutions using alkali-activated polypyrrole-based graphene oxide," Molecules, vol. 24 , no. 20 , p. 3685, 2019. 
[63] M. M. Ayad, W. A. Amer, S. Zaghlol, I. M. Minisy, P. Bober, and J. Stejskal, "Polypyrrole-coated cotton textile as adsorbent of methylene blue dye," Chemical Papers, vol. 72, no. 7, pp. 1605-1618, 2018

[64] A. A. Alghamdi, A.-B. Al-Odayni, N. A. Y. Abduh, S. A. Alramadhan, M. T. Aljboar, and W. S. Saeed, "Adsorptive performance of polypyrrole-based $\mathrm{KOH}$-activated carbon for the cationic dye crystal violet: kinetic and equilibrium studies," Adsorption Science and Technology, vol. 2021, article 5527594, pp. 1-11, 2021.

[65] P. Arabkhani, A. Asfaram, and M. Ateia, "Easy-to-prepare graphene oxide/sodium montmorillonite polymer nanocomposite with enhanced adsorption performance," Journal of Water Process Engineering, vol. 38, article 101651, 2020.

[66] H. Zheng, J. Qi, R. Jiang, Y. Gao, and X. Li, "Adsorption of malachite green by magnetic litchi pericarps: a response surface methodology investigation," Journal of Environmental Management, vol. 162, pp. 232-239, 2015.

[67] Y. Wang, Y. Zhang, C. Hou, and M. Liu, "Mussel-inspired synthesis of magnetic polydopamine-chitosan nanoparticles as biosorbent for dyes and metals removal," Journal of the Taiwan Institute of Chemical Engineers, vol. 61, pp. 292-298, 2016.

[68] A. C. Khorasani and S. A. Shojaosadati, "Magnetic pectinChlorella vulgaris biosorbent for the adsorption of dyes," Journal of Environmental Chemical Engineering, vol. 7, no. 3, article 103062, 2019.

[69] I. Ali, C. Peng, T. Ye, and I. Naz, "Sorption of cationic malachite green dye on phytogenic magnetic nanoparticles functionalized by 3-marcaptopropanic acid," RSC Advances, vol. 8, no. 16, pp. 8878-8897, 2018.

[70] A. A. Alqadami, M. Naushad, Z. A. Alothman, and T. Ahamad, "Adsorptive performance of MOF nanocomposite for methylene blue and malachite green dyes: kinetics, isotherm and mechanism," Journal of Environmental Management, vol. 223, pp. 29-36, 2018. 